\title{
Interfacial Adsorption of Monoclonal Antibody COE-3 at the Solid/Water Interface.
}

DOI:

10.1021/acsami.7b13332

\section{Document Version}

Accepted author manuscript

Link to publication record in Manchester Research Explorer

\section{Citation for published version (APA):}

Pan, F., Li, Z., Leyshon, T., Rouse, D., Li, R., Smith, C., Campana, M., Webster, JRP., Bishop, SM., Narwal, R., van, D. W. CF., Warwicker, J., \& Lu, JR. (2018). Interfacial Adsorption of Monoclonal Antibody COE-3 at the Solid/Water Interface. ACS Applied Materials and Interfaces, 10, 1306-1316.

https://doi.org/10.1021/acsami.7b13332

\section{Published in:}

ACS Applied Materials and Interfaces

\section{Citing this paper}

Please note that where the full-text provided on Manchester Research Explorer is the Author Accepted Manuscript or Proof version this may differ from the final Published version. If citing, it is advised that you check and use the publisher's definitive version.

\section{General rights}

Copyright and moral rights for the publications made accessible in the Research Explorer are retained by the authors and/or other copyright owners and it is a condition of accessing publications that users recognise and abide by the legal requirements associated with these rights.

\section{Takedown policy}

If you believe that this document breaches copyright please refer to the University of Manchester's Takedown Procedures [http://man.ac.uk/04Y6Bo] or contact uml.scholarlycommunications@manchester.ac.uk providing relevant details, so we can investigate your claim.

\section{OPEN ACCESS}


ACS Appl. Mater. Interfaces 2018, 10, 1306-1316

DOI: $10.1021 /$ acsami.7b13332

\section{Interfacial Adsorption of Monoclonal Antibody COE-3 at the Solid/Water Interface}

Fang $\operatorname{Pan}^{1}$, Zongyi Li ${ }^{1}$, Thomas Leyshon ${ }^{1}$, Dominic Rouse ${ }^{1}$, Ruiheng Li ${ }^{1}$, Charles Smith ${ }^{1}$, Mario Campana ${ }^{2}$, John R P Webster ${ }^{2}$, Steven M. Bishop ${ }^{4}$, Rojaramani Narwal ${ }^{4}$, Christopher F van der Walle ${ }^{3}$, Jim Warwicker ${ }^{5}$, Jian Ren Lu* ${ }^{1}$

${ }^{1}$ Biological Physics Laboratory, School of Physics and Astronomy, University of Manchester, Oxford Road, Schuster Building, Manchester M13 9PL, UK.

${ }^{2}$ ISIS Neutron Facility, STFC, Chilton, Didcot OX11 0QZ, UK.

${ }^{3}$ Formulation Sciences, MedImmune Ltd, Sir Aaron Klug Building, Granta Park, Cambridge CB21 6GH, UK

${ }^{4}$ Formulation Sciences, MedImmune LLC, Gaithersburg, MD 20878, USA.

${ }^{5}$ School of Chemistry, University of Manchester, Oxford Road, Chemistry Building, Manchester M13 9PL, UK.

*Corresponding author: Jian R Lu (email: j.lu@manchester.ac.uk; Tel: +44 161 2003926)

FP and ZL made equal contributions 


\begin{abstract}
Spectroscopic ellipsometry (SE) and neutron reflection (NR) data for the adsorption of a monoclonal antibody (mAb, termed COE-3, pI 8.44) at the bare $\mathrm{SiO}_{2} /$ water interface are here compared to simulations based on DLVO theory. COE-3 adsorption was characterized by an initial rapid increase in the surface adsorbed amount $(\Gamma)$ followed by a plateau. Only the initial rate of increase in $\Gamma$ was strongly correlated to the bulk concentration $(0.002-0.2$ $\mathrm{mg} / \mathrm{ml}$ ), with $\Gamma$ at plateau being about $2.2 \mathrm{mg} / \mathrm{m}^{2}$ (pH 5.5). Simulations captured COE-3 adsorption at equilibrium most accurately: the point at which the outgoing flux of molecules within the adsorbed plane matched the adsorption flux. Increasing buffer $\mathrm{pH}$ from 5.5 to 9 increased $\Gamma$ at equilibrium to $\sim 3 \mathrm{mg} / \mathrm{m}^{2}(0.02 \mathrm{mg} / \mathrm{ml} \mathrm{COE-3})$, revealing a dominant role for lateral repulsion between adsorbed mAb molecules. In contrast, increasing the buffer ionic strength $(\mathrm{pH}$ 6) reduced $\Gamma$, which was captured by simulations accounting for electrostatic screening by ions, in addition to $\mathrm{mAb} / \mathrm{SiO}_{2}$ attractive forces and lateral repulsion. NR data at the same bulk concentrations corroborated the SE data, albeit with slightly higher $\Gamma$ due to longer adsorption times for data acquisition, e.g. at $\mathrm{pH} 9, \Gamma$ was $3.6 \mathrm{mg} / \mathrm{m}^{2}(0.02 \mathrm{mg} / \mathrm{ml}$ COE-3), equivalent to a relatively high volume fraction of 0.5. An adsorbed monolayer of thickness of 50-52 $\AA$ was consistently determined by NR, corresponding to the short axial lengths of the Fab and Fc, and implying minimal structural perturbation. Thus, simulations enabled a mechanistic interpretation of the experimental data of mAb adsorption at the $\mathrm{SiO}_{2} /$ water interface.
\end{abstract}

\title{
Keywords:
}

mAbs, interfacial adsorption, antibody, structural unfolding, self-assembly, neutron reflection 


\section{Introduction}

The development of monoclonal antibodies (mAbs) in the 1970's has given rise to a novel class of biotherapeutics. ${ }^{1}$ Over the past 10 years, mAbs have become the dominant recombinant therapeutic proteins used in the clinic whilst many more are in the different stages of clinical trials. ${ }^{2,3}$ The basic molecular structure of a mAb is its 'Y-shape', comprised of 1 fragment crystallization $(\mathrm{Fc})$ and 2 fragment antigen-binding arms (Fabs). The two constant domains $\left(\mathrm{C}_{\mathrm{H}} \gamma 3\right.$ and $\left.\mathrm{C}_{\mathrm{H}} \gamma 2\right)$ of each heavy chain form the $\mathrm{Fc}$, and the $\mathrm{C}_{\mathrm{H}} \gamma 1$ and variable domain $\left(\mathrm{V}_{H}\right)$ together with the light chain $\mathrm{C}_{\mathrm{L}} \kappa / \lambda$ and $\mathrm{V}_{\mathrm{L}}$ domains form each Fab. Several crystalline structures of $\mathrm{Fc}$, Fab and whole $\mathrm{mAb}$ from various origins (different species, recombinant or bioengineered) have been reported over the past few decades. ${ }^{4-6}$

Sequence modifications based on recombinant and biochemical technologies can afford mAbs with new biological functions but also affect their secondary and tertiary structures, thereby imposing direct consequences on their physical stability. ${ }^{7,8}$ The surfaces of Fc and Fab segments are distributed with different amino acid groups that are polar, apolar and charged. As these groups are often distributed unevenly, mAb molecules are inherently amphiphilic, meaning that they can adsorb onto different interfaces and also become desorbed. Protein adsorption is a spontaneous process and depending on the exact nature of the interface, protein and solution conditions, adsorbed molecules can strongly interact with a particular substrate and between themselves within the adsorbed layers, resulting in structural deformation and unfolding of the protein. ${ }^{9}$ Although the exact mechanisms remain unclear, it is widely accepted that adsorption and desorption processes cause structural changes to proteins in solution and thereby promote aggregation. ${ }^{10}$ These molecular processes occur during $\mathrm{mAb}$ production, purification and storage in aqueous solution. Structurally deformed or partially unfolded $\mathrm{mAb}$ molecules can promote aggregation and sub-visible particulates, which must be characterized for injection products in accordance with the pharmacopoeias (e.g. USP <787> Subvisible Particulate Matter in Therapeutic Protein Injections). Thus, it is important to study surface and interfacial adsorption to understand the impact that sequence modifications may have.

Many mAbs such as COE-3 studied here are based on the immunoglobulin-1 (IgG1) isotype. Like all other candidate mAb therapeutics, COE-3 harbors substantial sequence modifications in the variable and constant domains of the Fab (Tables S1 and S2). While the interfacial properties of various mAbs have been reported, relating adsorption behavior to a specific $\mathrm{mAb}$ sequence is lacking in the literature. This study therefore makes an important contribution to the literature by reporting experimental and molecular modelling data 
together. We have studied the adsorption of COE-3 at the hydrophilic silicon oxide $\left(\mathrm{SiO}_{2}\right) /$ water interface, which is particularly relevant since the $\mathrm{SiO}_{2}$ surface is a good model of glass which is widely used to make vials and syringes for mAb products.

Protein adsorption at the solid/water interface has been studied by a number of groups using techniques such as ellipsometry, fluorescence and quartz crystal microbalance. ${ }^{11-16}$ These reports provide a useful consensus about the typical ranges observed for the amount of protein adsorbed and its physical state, under well-defined surface and solution conditions. Although these studies have demonstrated the relevance of adsorption and desorption processes to structural perturbation and solution aggregation, ${ }^{10-16}$ little insight about mAbs within the adsorbed layers have been reported. Neutron reflection (NR) is a powerful tool able to reveal the thickness and composition of multiple adsorbed protein layers. ${ }^{17-21}$ A key value of NR lies in its high depth resolution and therefore capability to determine the thickness and composition of the adsorbed layer(s) from which the structural conformation of the adsorbed molecules can be inferred. ${ }^{18,22,23}$ NR data together with the measured globular structures (e.g from X-ray crystal diffraction) of proteins enables us to determine the probable conformational orientations of the adsorbed protein molecules at a given interface, therefore also implying the extent of structural deformation and unfolding. ${ }^{18}$

However, each NR experiment generally requires a minimum of $30 \mathrm{~min}$ to acquire sufficient data for statistical analysis, making NR an impractical technique to follow a fast, dynamic adsorption process. In contrast, spectroscopic ellipsometry (SE) requires only seconds for each experiment and while it is highly sensitive to the adsorbed amount at a surface it cannot resolve the depth of adsorbed layer(s). Thus, coupling the excellent depth resolution that NR brings to dynamic adsorption monitored by SE, facilitates comparison of these combined data sets to computer 'simulations' (which could equally be described as 'iterated numerical calculations') of the equivalent protein adsorption event. This approach yields a mechanistic insight at the molecular level to a protein's surface and interfacial behaviour, that has to date not been fully realised. Building on our recent studies on the adsorption of COE-3 and its constituent $\mathrm{Fab}$ and $\mathrm{Fc}$ at the air/water interface, ${ }^{22,23}$ here we use NR and SE to characterize COE-3 adsorption at the bare $\mathrm{SiO}_{2}$ /water interface, comparing the data to computer simulations and so enabling a mechanistic interpretation of the adsorption process.

\section{Materials and experimental methods}

\subsection{Materials}




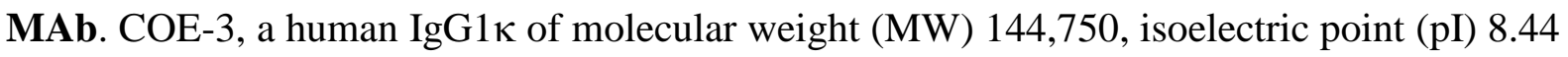
and extinction coefficient $1.43 \mathrm{ml} . \mathrm{mg}^{-1} \mathrm{~cm}^{-1}(280 \mathrm{~nm})$, was expressed in Chinese hamster ovary cells and purified using industry-standard methods. It was supplied as a stock solution of $46.4 \mathrm{mg} / \mathrm{ml}$ in 'His buffer' ( $25 \mathrm{mM}$ histidine/histidine hydrochloride, $7 \%$ w/v sucrose, $\mathrm{pH}$ 6.0), batch no. SP12-423, and stored at $-80{ }^{\circ} \mathrm{C}$ until solution preparation. The thawed solution was diluted directly into histidine buffer at a given $\mathrm{pH}$, maintaining an ionic strength of 25 $\mathrm{mM} ; \mathrm{H}_{2} \mathrm{O}$ buffers for a range of $\mathrm{pH}$ and COE-3 concentrations were used for SE measurements, with $\mathrm{D}_{2} \mathrm{O}$ buffers at the equivalent $\mathrm{pH}$ were prepared for NR measurements. Despite the original stock solution being in $\mathrm{H}_{2} \mathrm{O}$, the large dilutions made into $\mathrm{D}_{2} \mathrm{O}$ resulted in only very low percentages of $\mathrm{H}_{2} \mathrm{O}$, the exact amounts being taken into account during neutron data analysis. Table S1A gives the sequences of the light and heavy chains of COE-3 from which scattering length (SL) and scattering length density (SLD, $\rho$ ) in $\mathrm{D}_{2} \mathrm{O}$ can be calculated. Note that the solution behavior of COE-3 has been studied by Roberts et al. ${ }^{24}$ The $\mathrm{pH}$ dependent changes to the net charges on the $\mathrm{Fab}, \mathrm{Fc}$ and whole mAb were modelled without taking into account any charge contribution from the glycosylated groups (Figure S1).

Solvents and buffer. $\mathrm{D}_{2} \mathrm{O}(99 \% \mathrm{D})$, histidine and histidine hydrochloride were purchased from Sigma-Aldrich and used as supplied. $\mathrm{H}_{2} \mathrm{O}$ was processed using an Elgastat PURELAB water purification system. SL and SLD for $\mathrm{D}_{2} \mathrm{O}$ are also given in Table S1B.

Spectroscopic ellipsometry (SE). Interfacial adsorption was determined using a Woollam spectroscopic ellipsometer (J.A. Woollam Co. Inc). ${ }^{20,25}$ The SE measurements were performed over a wavelength range between 200 and $600 \mathrm{~nm}$. A special liquid cell with fused quartz windows was constructed to enable the SE measurements at the solid/liquid interface with the incident light beam at $70^{\circ}$. It facilitated the confinement of a $\langle 111>$ silicon wafer cut $(2 \mathrm{~cm} \times 2 \mathrm{~cm})$ in the central bottom of the liquid cell and thus enabled the reflection of incoming and existing light from its surface. Following the optical alignment in air, the thickness of the native oxide layer was first determined. The surface oxide layer was usually $12 \pm 3 \AA$ thick. Its precise value was obtained by fitting an optically transparent model with prefixed refractive index by assuming that the oxide layer contains no voids or defects and that its wavelength dispersion follows the Cauchy equation. The subsequent SE measurement in water would offer similar layer thickness within the error range, as this consistency indicated good window alignment. The cleaning of the liquid cell and regeneration of the 
oxide surface were undertaken by using 5\% dilution of neutral Decon solution as described for neutron blocking cleaning below.

The experimental data were analyzed using the software developed by J.A. Woollam Co. Inc. SE measured changes in the polarization state of light reflected from the surface of the sample from which information about layer thickness and refractive index could be revealed through the simultaneous analysis of two ellipsometric angles $\psi$ and $\Delta$, where $\psi$ denotes the change in amplitude and $\Delta$ denotes the phase of polarisation of the light after reflection in two components, the plane of reflection (p-plane), and that perpendicular to it (s-plane). The sample ellipticity, $\rho_{\mathrm{e}}$, is defined as the ratio of the Fresnel coefficients of the $\mathrm{p}$ and s planes $\left(\mathrm{R}_{\mathrm{p}}\right.$ and $\left.\mathrm{R}_{\mathrm{s}}\right)$ and is expressed as: ${ }^{20,25}$

$$
\rho_{\mathrm{e}}=\frac{\mathrm{R}_{\mathrm{p}}}{\mathrm{R}_{\mathrm{s}}}=\tan \Psi \mathrm{e}^{\mathrm{i} \Delta}
$$

The refractive index $n_{f}$ and the corresponding film thickness $\tau_{f}$ were subsequently calculated by the software using Equ. 1. The surface excess $\Gamma\left(\mathrm{mg} / \mathrm{m}^{2}\right)$ of the sample is finally calculated from $n_{f}$ and $\tau_{f}$ (in $\AA$ ) through Equ. $2:^{20,25,26}$

$$
\Gamma=\frac{\tau_{f}\left(n_{f}-n_{0}\right)}{(d n / d c)}
$$

where $n_{0}$ is the refractive index of the buffer, $d n / d c$ stands for the change of refractive index against solution concentration and a value of $0.18 \mathrm{ml} / \mathrm{g}$ was used in this work.

Neutron reflection (NR). Neutron reflectivity measurements were made on the SURF reflectometer at the ISIS Neutron Facility, STFC near Oxford, UK. Measurements were made using a single detector at fixed angles $(\theta)$ of $0.5,0.8$ and $1.8^{\circ}$ and for neutron wavelengths $(\lambda)$ in the range $0.5-6 \AA$ to provide a momentum transfer $(\mathrm{Q})$ range of $0.012-0.5 \AA^{-1}$, where $\mathrm{Q}$ $=4 \pi \sin \theta / \lambda$. The absolute reflectivity $(\mathrm{R})$ was calibrated with respect to the $100 \%$ reflectivity below the critical edge at the silicon/ $\mathrm{D}_{2} \mathrm{O}$ interface, and the background determined from the reflectivity at the limit of high $\mathrm{Q}\left(>0.25 \AA^{-1}\right)$. The $<111>$ silicon block used in NR measurements had approximate dimensions of $1.2 \times 4.0 \times 6.0 \mathrm{~cm}^{3}$. One of its large surfaces was polished by Crystran Ltd, Poole, UK. Before use, it was immersed in a Piranha solution (in a volume ratio of $6: 1$ for $\mathrm{H}_{2} \mathrm{SO}_{4}(98 \%)$ to $\mathrm{H}_{2} \mathrm{O}_{2}(35 \%)$ ) around $90{ }^{\circ} \mathrm{C}$ for 1 min to enhance its surface hydrophilicity. After being taken out and cooled down, it was washed with plenty of distilled water before it was placed in a $5 \%$ (w/w) solution of Decon 90 (Decon Ltd, UK) 
for $5 \mathrm{~min}$, followed by subsequent rinsing with a large amount of ultra-high quality water (UHQ). As shown previously, ${ }^{27}$ the cleaning process ensured the creation of a reproducible silicon oxide layer of thickness $12 \pm 3 \AA$. The same Decon washing was also used to help remove adsorbed $\mathrm{mAb}$ molecules and regenerate the silicon oxide surface between adsorption measurements. It has been shown previously that the reproducible surface properties could be reconfirmed by identical adsorption of lysozyme at $1 \mathrm{mg} / \mathrm{ml}, \mathrm{pH} 7 .^{28}$ The liquid trough used was processed from Perspex attached with flow system. It was clamped against the cleaned surface of the block. Solutions of buffer and $\mathrm{mAb}$ at different concentrations were introduced to the measuring surface from the flow system.

\subsection{Adsorption model}

The DLVO (Derjaguin, Landau, Verwey and Overbeek) theory states that the total Gibbs potential of interaction, when the interacting bodies are a distance $z$ apart, is given by:

$$
G_{i 2 j}(z)=G_{i 2 j}^{l w}(z)+G_{i 2 j}^{d a}(z)+G_{i 2 j}^{e l}(z)
$$

where the subscript $i 2 j$ refers to a body $i$ interacting with a body $j$ through a liquid medium 2 , and each term defines the contribution from one of the three forces involved: The Lifshiftzvan der Waals (LW), the donor-acceptor (DA) and the electrostatic (EL). ${ }^{29}$ In the model we consider two different bodies interacting with the COE-3 in solution: the silica wafer and the adsorbed layer of COE-3. Following standard practice, we treat the silica wafer as a semiinfinite plane (a sheet infinite in two dimensions) located in the $x-y$ plane at $z=0$ and the COE-3 in solution as hard spheres of fixed radius, $R .^{30}$ The adsorbed COE-3 layer is modelled as a fractional semi-infinite plane (FSIP) which evolves towards a true semi-infinite plane as the wafer reaches saturation. Under this assumption, each COE-3 that adsorbs is effectively smeared evenly over the entire semi-infinte plane. In each time interval in the model, a number of COE-3 molecules adsorb onto the silica wafer. This is represented as becoming trapped in the minimum of the Gibbs potential (at $z=a$ ) after which the proteinprotein Gibbs potential is added to the minimum, treated as a FSIP interacting with a hard sphere. Therefore, as more proteins become adsorbed the shape and depth of the minimum changes dramatically, and the change is heavily dependent on whether the protein-protein interactions are repulsive or attractive. Furthermore, the interactions caused by the adsorbed COE-3 layer were added to the minimum symmetrically, beginning from half the width of the well. This means that when a COE-3 molecule adsorbs, the value of its Gibbs energy 
distribution at a value of $\mathrm{z}$ equal to half the width of the well is added to the minimum of the current distribution. Then for $\mathrm{z}$ greater than the minimum in the current distribution, the values of the COE-3 distribution at $\mathrm{z}$ equal to half the width of the well plus the distance from the minimum are added. These same values are added for $\mathrm{z}$ values less the minimum, i.e. from the minimum to the silica wafer. Physically this corresponds to the FSIP of absorbed proteins forming in the $x-y$ plane within a layer of thickness equal to the width of the well, which the proteins are assumed to be able to occupy. The width of the minimum (the thickness of the adsorbed layer) was defined as the width of the well in the initial distribution, $\mathrm{G}_{123}(\mathrm{z})$ at a height equal to the root mean square (r.m.s) energy above the minimum in the current distribution, $\mathrm{G}_{\mathrm{N}}(\mathrm{z}$ ) (See Equ. 4). In this way we assume that the interactions experienced by a protein in the FSIP with the remainder of the FSIP cancels, but that when a protein is displaced from the FSIP (and so is attempting to desorb) this force no longer cancels in the $z$-direction and the protein experiences the potential in full. Hence, by letting a subscript 1 denote the silica wafer and a subscript 3 denote COE-3, the Gibbs potential experienced by an adsorbing protein when $N$ proteins are adsorbed is given by:

$$
\mathrm{G}_{\mathrm{N}}(\mathrm{z})=\mathrm{G}_{123}(\mathrm{z})+\frac{1}{\mathrm{~N}_{\max }} \sum_{n=1}^{N}\left\{\begin{array}{l}
\mathrm{G}_{323}\left(\frac{\mathrm{L}_{\mathrm{n}-1}}{2}+\left(\mathrm{z}-\mathrm{a}_{\mathrm{n}-1}\right)\right), \text { if } \mathrm{z} \geq \mathrm{a}_{\mathrm{n}-1} \\
\mathrm{G}_{323}\left(\frac{\mathrm{L}_{\mathrm{n}-1}}{2}-\left(\mathrm{z}-\mathrm{a}_{\mathrm{n}-1}\right)\right), \text { if } \mathrm{z} \leq \mathrm{a}_{\mathrm{n}-1}
\end{array}\right.
$$

where $N_{\max }$ is the number of proteins needed to saturate the silica wafer, and $a_{n}\left(L_{n}\right)$ is the position of the minimum of the distribution (width of the well) when $n$ proteins have adsorbed. The specific forms of each term of Equ. 4 and exemplar Gibbs distributions (Figure S4) can be found in Section S2A, but it should be noted that the LW and DA interactions are strongly influenced by the surface tensions between the two interacting bodies and the liquid medium. The EL interactions are instead influenced by the surface potentials of the bodies. All properties of the adsorption process are calculated from the Gibbs distribution. The flux of adsorbing proteins when the FSIP has $N$ proteins of a possible $N_{\max }$ is given by:

$$
\mathrm{F}_{\mathrm{N}}=\frac{\mathrm{DC}}{\int_{\mathrm{a}_{\mathrm{N}}}^{\mathrm{h}} \exp \left(\frac{\mathrm{G}_{\mathrm{N}}(\mathrm{z})}{\mathrm{k}_{\mathrm{B}} \mathrm{T}}\right) \mathrm{dz}}
$$

where $D$ is the diffusion coefficient, $C$ is the concentration of the proteins in the buffer, $h$ is the maximum height of the protein above the wafer (taken as $1 \mathrm{~cm}$ ) and $T$ is the temperature 
of the solution. The denominator of Equ. 5 can be interpreted as the resistance experienced by the proteins due to the Gibbs potential. ${ }^{31}$ Alternatively, one can interpret the denominator as a factor adjusting the concentration of COE-3 due to the presence of the Gibbs distribution, $\mathrm{G}_{\mathrm{N}}(\mathrm{z})$. For simplicity, the diffusion coefficient was taken to be that of water, $2.4 \times 10^{-9} \mathrm{~m}^{2} \mathrm{~s}^{-1}$ The desorption rate is dependent on two quantities. The first is the desorption attempt frequency, defined as the frequency at which an adsorbed protein collides with the wall of the minimum furthest from the silica surface. It is assumed that all adsorbed proteins have an energy equal to the r.m.s. energy above the minimum of the potential well, therefore the escape attempt frequency is:

$$
v_{\mathrm{N}}=2 \mathrm{~L}_{\mathrm{N}} / \mathrm{v}_{\mathrm{rms}}
$$

where $\mathrm{v}_{r m s}$ is the r.m.s. velocity. The second quantity is the probability that a desorption attempt is successful. This is the probability of the protein having sufficient kinetic energy to overcome the barrier needed to escape from the potential well at temperature $T$, given that it has the r.m.s. kinetic energy above the minimum of the well, and is denoted as $P_{N}$. This is calculated from the Maxwell-Boltzmann distribution. Hence, the total change in the number of adsorbed proteins in a time interval $\Delta t$, if there were $N$ adsorbed proteins at the beginning of the interval, is:

$$
\Delta \mathrm{N}=\frac{\mathrm{F}_{\mathrm{N}}}{\mathrm{m}} \mathrm{A}\left(1-\frac{\mathrm{N}}{\mathrm{N}_{\max }}\right) \Delta \mathrm{t}-v_{\mathrm{N}} \mathrm{P}_{\mathrm{N}} \mathrm{N} \Delta \mathrm{t}
$$

where $A$ is the area of the silica wafer, $\left(1-N / N_{\max }\right)$ is the fractional area of the silica wafer available for adsorption and $m$ is the mass of each COE-3 molecule. The flux, $\mathrm{F}_{\mathrm{N}}$ is calculated in units of mass per unit area per unit time, and so dividing by mass will give the change in number of adsorbed proteins. In Equ. 7 the first term is the number of adsorbing proteins and the second term is the number of desorbing proteins. Due to the number of proteins involved, Equ. 4 is in practice only computed for certain values of completion of the FSIP, rather than for each individual protein. After calculating $N(t)$ iteratively using Equ. 7 , the surface adsorbed amount is calculated via:

$$
\Gamma(\mathrm{t})=\mathrm{N}(\mathrm{t}) \mathrm{m} / \mathrm{A}
$$


The model assumes that the buffer solution is static, such that the only motion that the COE-3 molecules exhibit is diffusive, which can be enhanced or reduced by the Gibbs distribution. This therefore implies that our model is a diffusion transfer process.

\subsection{Model parameters}

When COE-3 was added from low concentration $(25 \mathrm{mM})$ histidine buffer, the measured change in the total surface tension was almost zero (see Figure S3). Hence we conclude that the total surface tension must be similar to that of water, at $72.8 \mathrm{mN} / \mathrm{m}$, and that the buffer can be modelled as water when at low COE-3 concentrations. Further restrictions on the individual components of the surface tension (that is, the Liftshitz-van der Waals, $\gamma^{1 \mathrm{w}}{ }_{3}$ and donor, $\gamma_{3}^{\mathrm{d}}$ and acceptor, $\gamma_{3}^{\mathrm{a}}$ components) could be enforced by assuming that protein-protein interactions are repulsive, which avoids aggregation once in solution, and by requiring a minimum to form in the initial Gibbs distribution, permitting adsorption. From the remaining valid parameters (illustrated in Figure S5) the set in which the interactions gave sufficient strength in protein-protein repulsion to replicate the experimental data were $\gamma^{1 \mathrm{w}}{ }_{3}=24.35$ $\mathrm{mN} / \mathrm{m}, \gamma_{3}^{\mathrm{d}}=31.05 \mathrm{mN} / \mathrm{m}$ and $\gamma_{3}^{\mathrm{a}}=18.90 \mathrm{mN} / \mathrm{m}$. The set of valid parameters was large, but finite, and does have significant influence on the calculation of the results because they have control over the Gibbs distribution. Therefore, the set chosen should not be viewed as the definite values of surface tensions for COE-3, but the set which will enable these calculations to give us an understanding of how particular aspects of the experiments, such as $\mathrm{pH}$ or ionic strength, affect the adsorption process. A more detailed discussion of this choice can be found in Section S2B. The surface tension components of water are $\gamma^{\mathrm{lw}}{ }_{2}=21.80 \mathrm{mN} / \mathrm{m}, \gamma_{2}^{\mathrm{d}}=25.50$ $\mathrm{mN} / \mathrm{m}$ and $\gamma_{2}^{\mathrm{a}}=25.50 \mathrm{mN} / \mathrm{m}$ and those of silica are $\gamma^{1 \mathrm{w}}{ }_{1}=39.00 \mathrm{mN} / \mathrm{m}, \gamma_{1}^{\mathrm{d}}=4.10 \mathrm{mN} / \mathrm{m}$ and $\gamma_{1}^{\mathrm{a}}=0.80 \mathrm{mN} / \mathrm{m}$, which are well documented. ${ }^{29}$

We assumed COE-3 to be a hard sphere protein, for which we took the radius of COE-3 to be the average of its Fab and Fc constituents, which results in a radius of $56 \AA$. For simplicity we assumed that the radius of COE-3 in solution was not affected by buffer $\mathrm{pH}$ and ionic strength, but that the effective area occupied by each molecule when adsorbed was. In doing this we account for conformational changes in the lateral COE-3 repulsion within the adsorbed layer. Table 1 states the effective radii which were calculated from the experimental data for the equilibrated values of the $0.2 \mathrm{mg} / \mathrm{ml}$ adsorption curves of Figure 4(b) and Figure 6(b). The high concentration curves were chosen as these gave a more accurate description of 
how equilibrated values depend on $\mathrm{pH}$ and ionic strength, because mAb concentration was high enough that influence from further increase was negligible.

\begin{tabular}{|c|c||c|c|}
\hline $\mathrm{pH}$ & $\begin{array}{c}\text { Effective radius }(\AA) \\
\text { at I = 25 mM }\end{array}$ & $\begin{array}{c}\text { Ionic strength }(\mathrm{mM}) \\
\text { at } \mathrm{pH} 6\end{array}$ & Effective radius $(\AA)$ \\
\hline 5.0 & 59.5 & 5 & 56.5 \\
\hline 5.5 & 58.9 & 13.3 & 57.5 \\
\hline 6.0 & 58.3 & 25 & 58.3 \\
\hline 7.0 & 53.5 & 50 & 61.0 \\
\hline 8.0 & 49.4 & 100 & 73.0 \\
\hline 9.0 & 49.0 & & \\
\hline
\end{tabular}

Tables 1. Effective radii used for COE-3 for varying buffer parameters: different buffer $\mathrm{pH}$ at ionic strength (I) $25 \mathrm{mM}$, and different buffer ionic strength at $\mathrm{pH} 6$.

\section{Results and discussion}

\subsection{Dynamic adsorption}

Prior to monitoring COE-3 adsorption it was necessary to characterize the silicon substrate surface, which bears a native oxide layer whose thickness was determined by SE. If pores were absent, the refractive index would correspond to the $100 \%$ silicon oxide. For all the wafer cuts used, the native oxide layers were found to be $12-14 \AA$ thick, without any sign of porous defects or requirement to incorporate a parameter for roughness during data fitting. The smooth oxide layer was also confirmed by NR measurements in $\mathrm{D}_{2} \mathrm{O}$.

Subsequent SE measurements were made to investigate the time-dependent adsorption of COE-3 at pH 5.5 and ionic strength $25 \mathrm{mM}, 20-21{ }^{\circ} \mathrm{C}$. An exemplar set of SE measurements is shown in Figure 1, where the amplitude component $\Psi$ is shown in Figure 1(a) and the phase difference $\Delta$ is shown in Figure 1(b). Because each pair of $\Psi$ and $\Delta$ could be measured in 10-15 s, SE is ideal for following the dynamic adsorption process. As evident from Figure 1 , whilst changes from $\Psi$ were not so obvious, clear differences were observed in $\Delta$. These SE measurements were undertaken with COE-3 at $0.02 \mathrm{mg} / \mathrm{ml}$ in bulk solution, with similar measurements made at other concentrations under the same solution conditions. An exemplar set of concentration effects is shown in Figure S2, measured after 5 min of adsorption. Again, changes in $\Psi$ are small but differences in $\Delta$ are obvious, similar to the situation as described in Figure 1.

The amount of protein adsorption was obtained from data fitting following the procedure as described in the Materials and Experimental Method and the wavelength $(\lambda)$ dependence of the refractive index $n$ is taken into account using the Cauchy dispersion equation: ${ }^{32}$ 


$$
n(\lambda)=\mathrm{A}-\frac{\mathrm{B}}{\lambda^{2}}
$$

where $\mathrm{A}$ is typically 1.45 and $\mathrm{B}$ is taken to be $0.003 \mu \mathrm{m}^{2}$. The time-dependent adsorption as obtained from the above described data analysis process is shown in Figure 2(a) where it can be seen that the rate of adsorption increases with the mAb concentration; at $2 \times 10^{-3} \mathrm{mg} / \mathrm{ml}(2$ ppm), very little adsorption is detected over the first $60 \mathrm{~min}$, while at $5 \times 10^{-3} \mathrm{mg} / \mathrm{ml}$, adsorption increased steadily in a linear fashion over the first $40 \mathrm{~min}$ with a plateau at around $2 \mathrm{mgm}^{-2}$. The initial rate of adsorption further increased with increasing concentration to $1 \times 10^{-2}$ and $2 \times 10^{-2} \mathrm{mg} / \mathrm{ml}$, reaching a plateau (saturation) after the first 20 and $10 \mathrm{~min}$, respectively. At and above $5 \times 10^{-2} \mathrm{mg} / \mathrm{ml}$, the adsorption profiles overlapped, with saturation being reached within the first minute.

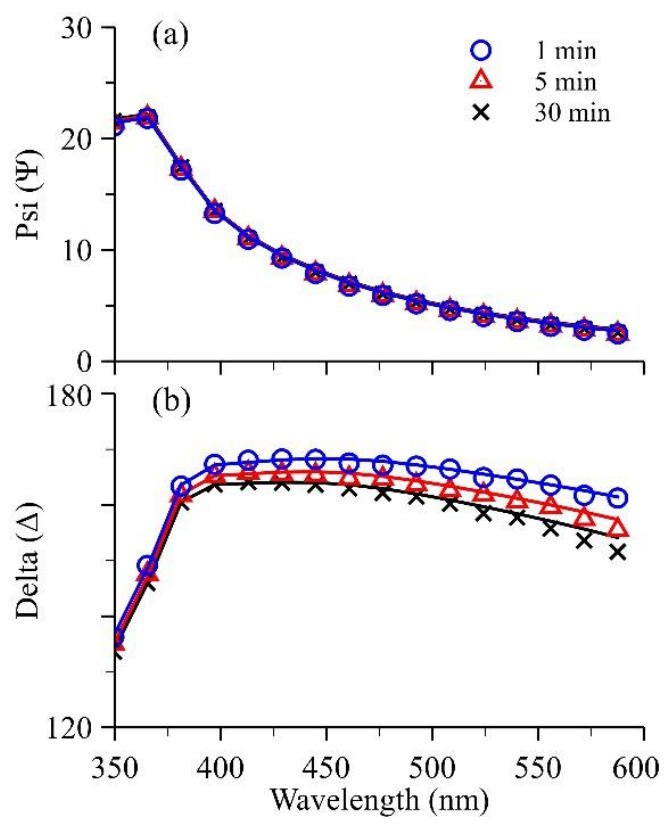

Figure 1. Ellipsometric scans of the amplitude component $\Psi$ (a) and the phase difference $\Delta$ (b) against wavelength measured at the $\mathrm{SiO}_{2} /$ water interface for $0.02 \mathrm{mg} / \mathrm{ml} \mathrm{COE}-3$ in $25 \mathrm{mM}$ His buffer, $\mathrm{pH} 5.5$; after 1,5 and $30 \mathrm{~min}$ of adsorption. The continuous lines show the uniform layer fits.

At the concentration of $0.02 \mathrm{mg} / \mathrm{ml}(20 \mathrm{ppm})$, the adsorbed amount of COE-3 at the bare silicon oxide/water interface was calculated to be $2.2 \mathrm{mg} / \mathrm{m}^{2}$ (Figure 2b). From Equ. 12 and with the molecular weight (MW) of 144,750 from Table S1B, this is equivalent to an area per molecule of 11,000 $\AA^{2}$. COE-3 is comprised of 1 Fc and 2 Fabs, and the dimensions of the Fc and Fab from the crystalline structure are $65 \times 70 \times 40$ and $85 \times 45 \times 45 \AA^{3}$, respectively. ${ }^{4,5}$ On the assumption that the globular fold is maintained and COE-3 adsorbed 'sideways-on' with the shortest axes projected perpendicular to the interface and without any domains stacking, then the Fc would occupy a limiting area of about $4600 \AA^{2}$ and each Fab about $4000 \AA^{2}$, reaching 
a value of $12600 \AA^{2}$. As this theoretical adsorbed area is very close to the limiting values estimated, the mAb fragments within the adsorbed layer must be very closely packed.

In a separate study, we have examined the adsorption of COE-3 on surface of water using neutron reflection. ${ }^{22,23}$ It was found that the adsorbed mAb occupied an area per molecule of $12000 \AA^{2}$ at the mAb concentration of $0.1 \mathrm{mg} / \mathrm{ml}$ under same solution $\mathrm{pH}$ and ionic strength. In addition, $\mathrm{mAb}$ molecules formed a uniform layer thickness of some $50 \AA$. At these relatively high concentrations, the similarity in adsorption between these two interfaces implies that the limiting area was dictated by the horizontal mAb-mAb packing and that the saturated adsorption was little affected by the different substrates (air versus $\mathrm{SiO}_{2}$ ).

In contrast, below $5 \times 10^{-2} \mathrm{mg} / \mathrm{ml}$, the two substrates affected $\mathrm{mAb}$ adsorption very differently. Whilst little adsorption was detected at $2 \times 10^{-3} \mathrm{mg} / \mathrm{ml}$ at the $\mathrm{SiO}_{2} /$ water interface, the equilibrated adsorbed amount was about $0.9 \mathrm{mgm}^{-2}$ on the surface of water. Furthermore, at $5 \times 10^{-3} \mathrm{mg} / \mathrm{ml}$ the saturated adsorption tended to $2 \mathrm{mgm}^{-2}$ at the $\mathrm{SiO}_{2} /$ water interface but 1-1.2 $\mathrm{mgm}^{-2}$ at the air/water interface. Between $5 \times 10^{-3}$ and $5 \times 10^{-2} \mathrm{mg} / \mathrm{ml}$, COE-3 adsorption at the air/water interface slowly increased to saturation, whilst adsorption at the $\mathrm{SiO}_{2} /$ water interface had already reached saturation (albeit after $60 \mathrm{~min}$ ). This implies two different concentration dependent adsorption processes, most likely reflecting their different physical natures: adsorption below $5 \times 10^{-3} \mathrm{mg} / \mathrm{ml}$ at the air/water interface is driven by the amphiphilicity of the $\mathrm{mAb}$, whilst adsorption at the $\mathrm{SiO}_{2} /$ water interface is driven by the opposite charges between the $\mathrm{SiO}_{2}$ surface and the mAb at weakly acidic $\mathrm{pH}$.

Figure 2(c) shows exemplar NR profiles measured at 10,30 and 60 min upon the contact of $\mathrm{mAb}$ solution with the substrate surface. In this case, each NR run took 8-10 min to complete. As it can be seen from Figure 2(c), the difference between the reflectivity profiles measured over the dynamic adsorption period is very small. For a uniformly adsorbed layer under water, the volume fraction of $\mathrm{mAb}\left(\phi_{p}\right)$ and its surface excess $\left(\Gamma_{p}, \mathrm{in} \mathrm{mg} / \mathrm{m}^{2}\right)$ within the layer can be calculated on the basis of the following equations: ${ }^{21}$

$$
\begin{gathered}
\phi_{p}=\frac{\rho-\rho_{w}}{\rho_{p}-\rho_{w}} \\
\Gamma_{p}=0.1 \phi_{p} \tau \rho_{p}{ }^{\prime}
\end{gathered}
$$

where $\rho$ is the best fitted layer SLD, $\rho_{W}$ and $\rho_{p}$ are the SLD for water and mAb, respectively, $\tau$ (in $\AA$ ) is the layer thickness and $\rho_{p}{ }^{\prime}$ is the density of the $\mathrm{mAb}$ and is equivalent to $\frac{M W}{V}$, 
where MW is in $\mathrm{g} / \mathrm{mol}$ and $\mathrm{V}$, its molecular volume, is in $\mathrm{g} / \mathrm{cm}^{3}$. The area per molecule (A, in $\AA^{2}$ ) can be obtained using:

$$
A_{p}=\frac{M W}{6.023 \Gamma_{p}}
$$

where the constant of 6.023 is related to the conversion of the Avogadro's number and the unit difference between Angstrom $(\AA)$ and meter (m). Equ. 4 specifies that the antibody layer is filled by the solvent, with the total of the antibody volume fraction $\left(\phi_{p}\right)$ and solvent volume fraction $\left(\phi_{w}\right)$ being equal to unity. To ensure the SLD contributions consistent to the interfacial composition the following equations must be conserved: ${ }^{18-21}$

$$
\rho=\rho_{p} \phi_{p}+\rho_{w} \phi_{w}
$$

The best uniform layer fits as shown in Figure 2(c) led to the pairs of $\rho$ and $\tau$ for the 3 different sets of reflectivity data measured under the specified time points from which $\Gamma_{p}$ could be obtained from Equ. 3 and 4. The surface adsorbed amount from these short NR profiles is shown in Figure 2(b) where it can be seen that both SE and NR data are in good agreement within the experimental errors. 


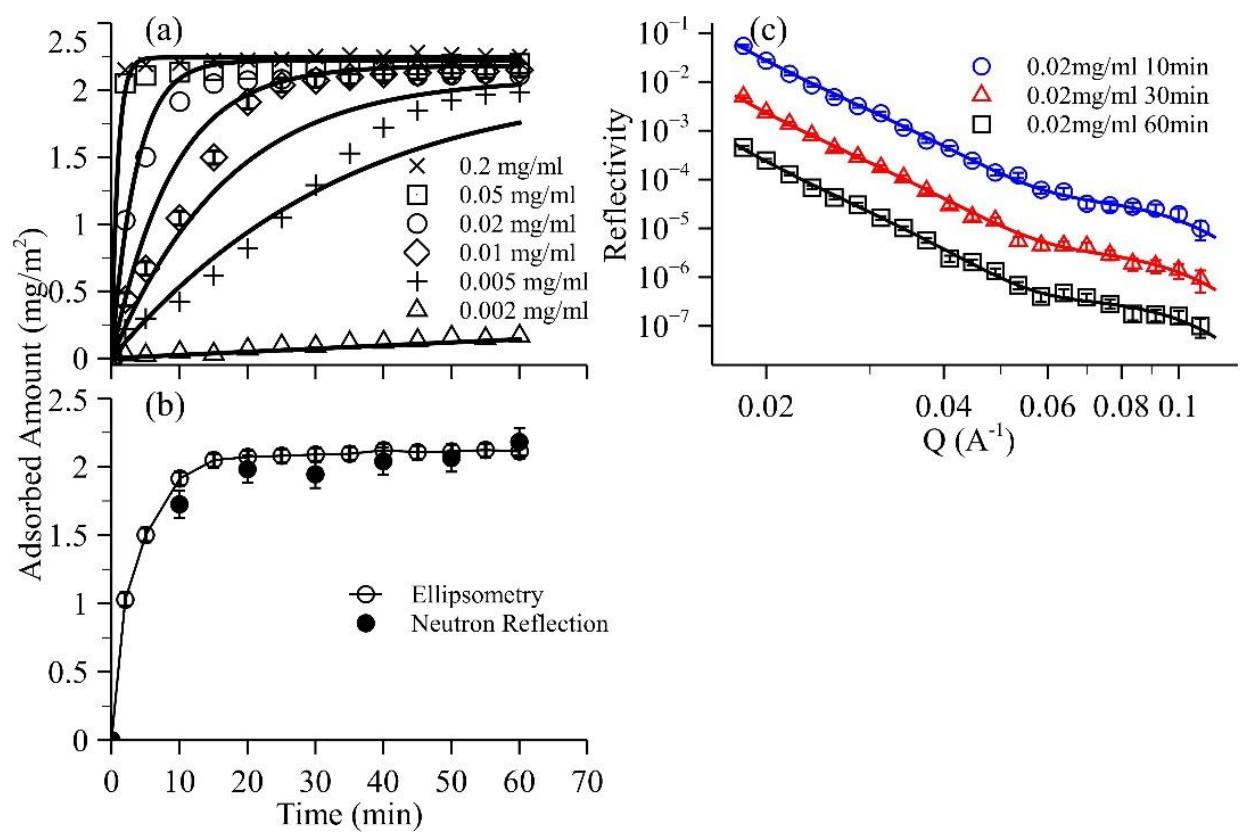

Figure 2. (a) SE measurements of surface adsorbed amount $(\Gamma)$ of $\mathrm{COE}-3$ plotted against time at the $\mathrm{SiO}_{2}$ /water interface, in $25 \mathrm{mM}$ His buffer, $\mathrm{pH} 5.5,20-21^{\circ} \mathrm{C}$, at concentrations as indicated. Plotted lines are simulations produced at the same concentrations with the exception of $2 \times 10^{-3} \mathrm{mg} / \mathrm{ml}$ for which an effective concentration of $2 \times 10^{-4} \mathrm{mg} / \mathrm{ml}$ was used; (b) comparison of the adsorbed amount of COE-3 at $0.02 \mathrm{mg} / \mathrm{ml}$ bulk concentration plotted against time and measured by SE and NR; (c) NR profiles measured at the $\mathrm{SiO}_{2} / \mathrm{D}_{2} \mathrm{O}$ interface after 10, 30 and $60 \mathrm{~min}$ COE-3 adsorption from $0.02 \mathrm{mg} / \mathrm{ml}$ bulk concentration, buffer as in (a). The continuous lines denote the best uniform fits as described in the text. For clarity, the reflectivity profiles at 30 and 60 min were divided by 10 and 100 .
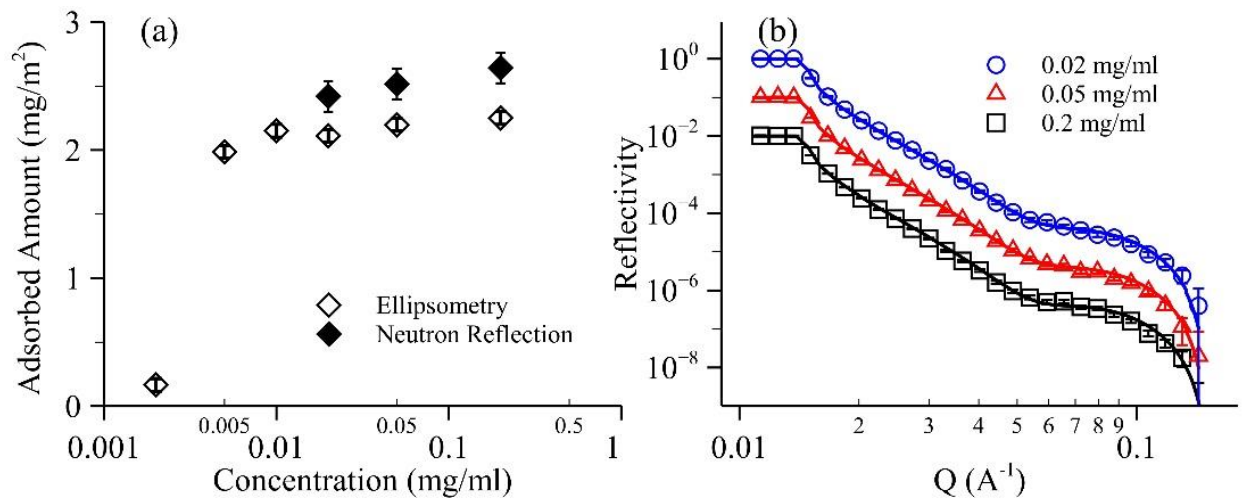

Figure 3. (a) Surface adsorbed amount $(\Gamma)$ measured by $\mathrm{SE}$ after $60 \mathrm{~min}$ adsorption and by NR after 3-4 hr adsorption; (b) NR profiles measured at the $\mathrm{SiO}_{2} / \mathrm{D}_{2} \mathrm{O}$ interface for COE-3 adsorption from $0.02,0.05$ and $0.2 \mathrm{mg} / \mathrm{ml}$ bulk concentration, buffer as in Fig. 2(a). The continuous lines denote the best uniform layer fits with thicknesses of $50 \pm 2 \AA$ and adsorbed amount plotted in (a). For clarity, the reflectivity profiles measured at 0.05 and $0.2 \mathrm{mg} / \mathrm{ml}$ were divided by 10 and 100 . 


\begin{tabular}{|c|c|c|c|c|c|}
\hline $\begin{array}{c}\text { Conc } \\
(\mathrm{mg} / \mathrm{ml})\end{array}$ & $\begin{array}{c}\tau \pm 3 \\
/ \AA\end{array}$ & $\begin{array}{c}\mathrm{SLD} \pm 0.02 \\
/ 10^{-6} \AA^{-2}\end{array}$ & $\begin{array}{c}\phi_{p} \\
\pm 0.03\end{array}$ & $\begin{array}{c}\mathrm{A}_{\mathrm{p}} \pm 200 \\
/ \AA^{2}\end{array}$ & $\begin{array}{c}\Gamma \pm 0.1 \\
/ \mathrm{mgm}^{-2}\end{array}$ \\
\hline 0.02 & 50 & 5.28 & 0.34 & 9900 & 2.4 \\
\hline 0.05 & 51 & 5.23 & 0.35 & 9600 & 2.5 \\
\hline 0.2 & 52 & 5.19 & 0.37 & 9100 & $2.6^{5}$ \\
\hline
\end{tabular}

Table 2: Structural parameters obtained from best uniform layer fits to the NR profiles shown in Figure 3(b), relating to Equ. 10-13.

\subsection{Effect of $m A b$ concentration}

From Figure 2(a) it is clear that after 60 min the adsorbed amount of COE-3 reached a plateau for concentrations $>5 \times 10^{-3} \mathrm{mg} / \mathrm{ml}$. The adsorbed amount at $60 \mathrm{~min}$ or above can therefore be considered the equilibrated value at a given concentration; this value being 2 $\mathrm{mg} / \mathrm{m}^{2}$ for all concentrations $\geq 5 \times 10^{-3} \mathrm{mg} / \mathrm{ml}$.

In the simulations, an effective concentration that was an order of magnitude smaller than the experimental protein concentration of $2 \times 10^{-3} \mathrm{mg} / \mathrm{ml}$ resulted in a significantly better fitting to the measured adsorption data. When the COE- 3 concentration of $2 \times 10^{-3} \mathrm{mg} / \mathrm{ml}$ was used in simulations, the curve produced was still of the same shape (with roughly constant gradient) but would reach a significantly higher adsorbed amount after 90 minutes. This indicates that in solutions with very low protein concentrations, a relatively large proportion of the COE-3 remains attached to the sides of its storage container, instead of being available in the solution for adsorption. This means that the effective concentration of COE- 3 used in the $2 \times 10^{-3}$ $\mathrm{mg} / \mathrm{ml}$ experiment was nearer $2 \times 10^{-4} \mathrm{mg} / \mathrm{ml}$. Other than the lowest concentration, the simulations show a good match to the equilibrated adsorbed amounts. Since only concentration was varied, all curves were produced with the same effective radius. The simple model does not capture the full effect of the initial adsorption process. At lower adsorbed amounts the number of adsorbed proteins will not be great enough to justify the assumption of formation of a FSIP. This would likely result in an overestimation of the repulsive protein-protein interactions, causing initial adsorption to be reduced relative to the experimental values. This discrepancy was observed in the initial adsorption region corresponding to the medium and high COE-3 concentrations studied and is more visible in Figure 4(a).

NR measurements of COE-3 adsorption from $0.02,0.05$ and $0.2 \mathrm{mg} / \mathrm{ml}$ bulk concentration reveal very little difference in layer thickness and composition (Figure 3b). A uniform layer model was sufficient to represent the main features, with $\Gamma$ of $2.4,2.5$ and $2.65 \mathrm{mg} / \mathrm{m}^{2}$, respectively (Table 2). As evident from Figure 3(a), these NR values are slightly higher than 
their respective values measured by SE, which probably arise from the different adsorption times: NR data were collected 3-4 hr after COE-3 was introduced to the substrate surface, with SE data collected $1 \mathrm{hr}$ after.

\subsection{Effect of solution $p H$}

COE-3 adsorption profiles at $\mathrm{pH}$ values from 5 to 9, measured by $\mathrm{SE}$, showed an initial fast adsorption phase followed by plateau (Figure 4(a) and 4(b)). A clear change in the absorbed amount as a function of $\mathrm{pH}$ was observed for both concentrations tested, this being around 2, 2.5 and $3 \mathrm{mg} / \mathrm{ml}$ for $\mathrm{pH}<7,7$ and $>7$, respectively. The ten-fold increase in concentration caused a greater rate of adsorption, as observed above (Figure 2(a)), with only a small increase in the absorbed amount at plateau. Saturation of adsorbed COE-3 had therefore been reached even at $0.02 \mathrm{mg} / \mathrm{ml}$ (after $\sim 50 \mathrm{~min}$ ), with the small increase seen at $0.2 \mathrm{mg} / \mathrm{ml}$ most likely representing a slow relaxation process during which the adsorbed COE-3 molecules became rearranged (but not necessarily structurally deformed) with the layer.

The continuous lines shown in Figure 4 denote the best fitted curves using the same model as described above by taking into account the $\mathrm{pH}$ dependent charge changes on $\mathrm{COE}-3$ and the surface. It can again be seen from Figure 4 that whilst the fits can represent the final adsorbed amount well, they tend to underestimate the adsorbed amount over the initial adsorption processes. This situation is more evident from Figure 4(a). As already explained, this discrepancy was caused by the overestimation of the interactions associated with inadequate assumption of the FSIP model. But at the high COE-3 concentration relating to Figure 4(b), the dynamic adsorption occurred much faster and the surface was more quickly filled with more COE-3 molecules, making the FSIP model more applicable with respect to the experimental time scale undertaken by SE and resulting in better model fitting.

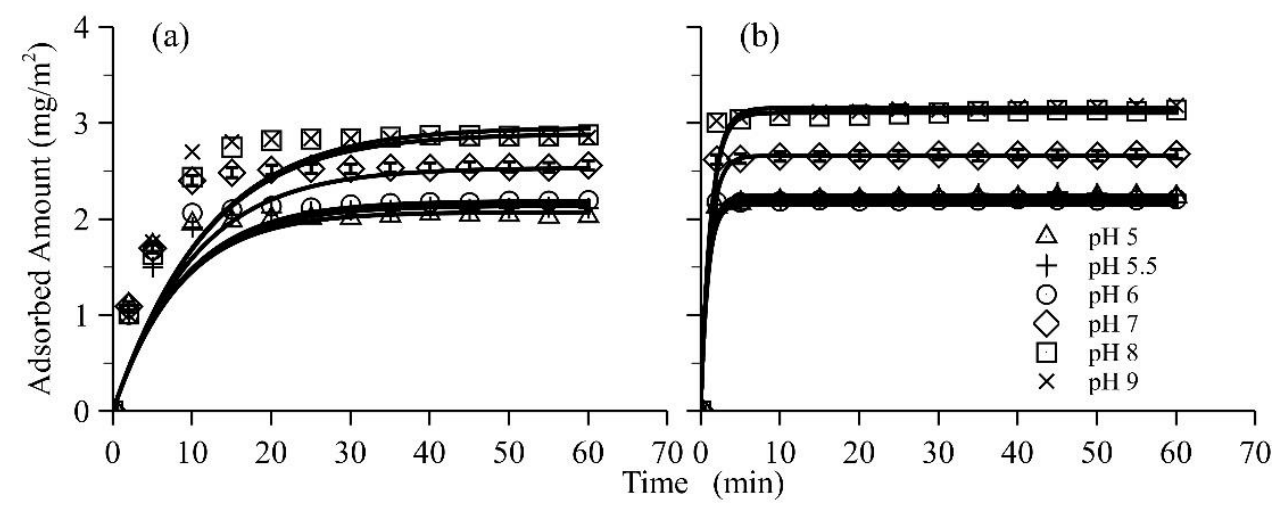

Figure 4. Surface adsorbed amount $(\Gamma)$ plotted against time measured by $S E$ at the $\mathrm{SiO}_{2} /$ water interface for COE-3 at (a) $0.02 \mathrm{mg} / \mathrm{ml}$ and (b) $0.2 \mathrm{mg} / \mathrm{ml}$, in $25 \mathrm{mM}$ His buffer, 20$21^{\circ} \mathrm{C}$ and $\mathrm{pH}$ as indicated. The solid lines represent the simulated curves. 
From these SE data, the adsorbed amount of COE-3 can be seen to have reached an equilibrium after $60 \mathrm{~min}$. Figure 5(a) shows the equilibrated adsorption plotted versus COE-3 concentration at $\mathrm{pH}$ 5.5, 7 and 9, whilst Figure 5(b) shows the equilibrated adsorption plotted versus solution $\mathrm{pH}$ at COE-3 concentrations of 0.02 and $0.2 \mathrm{mg} / \mathrm{ml}$. It is apparent that the $\mathrm{SiO}_{2}$ surface becomes saturated at bulk concentrations $\leq 0.01 \mathrm{mg} / \mathrm{ml}$ independent of $\mathrm{pH}$, with the effect of $\mathrm{pH}$ seen as a change in the saturated amount absorbed. This $\mathrm{pH}$ trend is more clearly seen from Figure 5(b) which shows a greater range of $\mathrm{pH}$ values; the higher amount absorbed at equilibrium follows the shift from mildly acidic to basic conditions at low and high concentrations.

Over the $\mathrm{pH}$ range studied, the bare $\mathrm{SiO}_{2}$ surface bears weak negative charges and its charge density rises with $\mathrm{pH}$ above $\mathrm{pH} 7-8$. In contrast, $\mathrm{COE}-3$ carries net positive charge at $\mathrm{pH} \leq 8$ (pI 8.44). ${ }^{24}$ As the polypeptide sequences for both light and heavy chains are known (Table $\mathrm{S} 1 \mathrm{~A}$ ), the $\mathrm{pH}$ dependent charges for Fab, Fc and the whole COE-3 can be calculated (Figure S1), and shown to be quite different. For the whole COE-3, the decrease in net charge with increasing $\mathrm{pH}$ corresponds to a steady rise in the amount adsorbed. This is most obvious at $\mathrm{pH} 9$ where the highest surface adsorbed amount is reached: $3.6 \mathrm{mg} / \mathrm{m}^{2}$ which is equivalent to an area per molecule of $6700 \AA^{2}$ (Figure 5b).

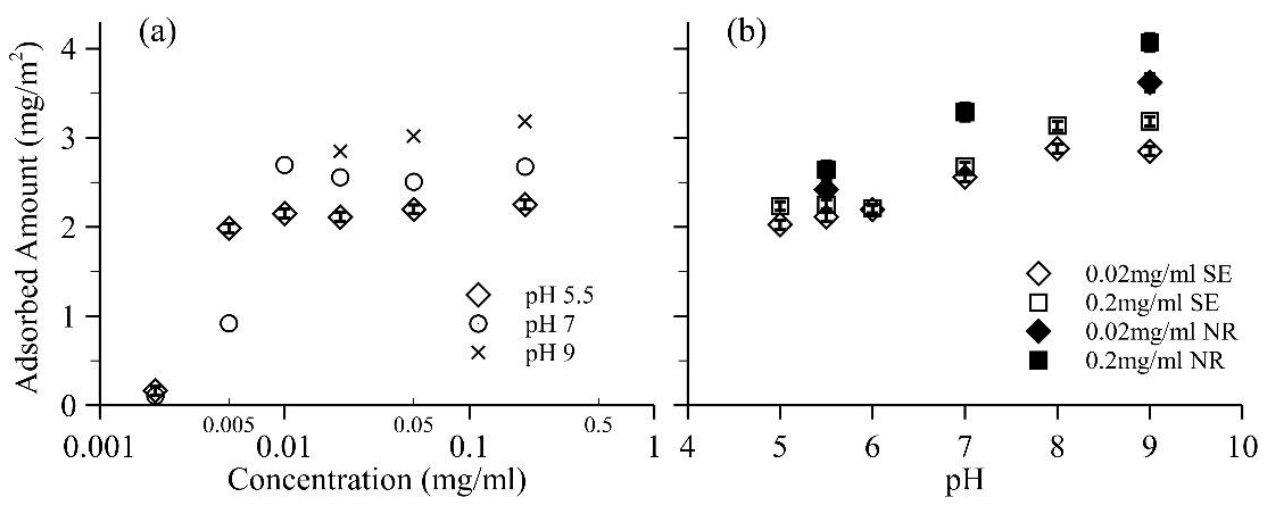

Figure 5. Surface adsorbed amount of COE- 03 measured at $60 \mathrm{~min}$ plotted against concentration for $\mathrm{pH} 5.5,7$ and 9 (a), and against $\mathrm{pH}$ with concentrations of 0.02 and 0.2 $\mathrm{mg} / \mathrm{ml}$ (b), in $25 \mathrm{mM}$ His buffer, $20-21{ }^{\circ} \mathrm{C}$, measured by SE and NR as indicated.

As the bare $\mathrm{SiO}_{2}$ surface and COE-3 molecules are of opposite charges, electrostatic attraction is the main driving force for initiating interfacial adsorption. However, as more $\mathrm{mAb}$ molecules are adsorbed, lateral repulsion within the adsorbed layer occurs, constraining the maximal amount of COE-3 molecules that can be adsorbed. Given the relationship between COE-3 net charge and $\mathrm{pH}$, lateral repulsion emerges as the key mechanism by which COE-3 adsorption at equilibrium is limited. This is consistent with previous observations for 
other proteins. ${ }^{18-23}$ These results were also obtained in the simulations showing that the dominant influence to equilibrated values is the effective area of adsorbed COE-3, with adjustments caused by the $\mathrm{pH}$ induced changes to electrostatic interactions involving adsorbing COE-3 molecules as indicated by changes in equilibrated values in Figures 4(a) and 4(b).

\subsection{Effect of solution ionic strength}

Figure 6 shows the time-dependent adsorption of COE-3 at the $\mathrm{SiO}_{2} /$ water interface measured by SE for different buffer ionic strengths and $\mathrm{mAb}$ concentrations. The profiles in general reflect those acquired at various $\mathrm{pH}$, being characterized by an initial fast adsorption phase and subsequent slow relaxation process at the plateau, reached between 2-15 min dependent on COE-3 concentration. The buffer ionic strength had little effect on the initial absorption phase for a given concentration but clearly changed the amount of COE-3 absorbed at equilibrium. At both high and low COE-3 concentrations, the adsorption profiles at 5 and 13 $\mathrm{mM}$ ionic strength overlap and a small drop in $\Gamma$ is observed at $25 \mathrm{mM}$, following which much larger falls in $\Gamma$ occur. The COE-3 bulk concentration is clearly the main driving force during the initial fast adsorption process. Over the plateau region, the dominant role is played by electrostatic interactions which are screened out at both the substrate and mAb surfaces as ionic strength increases, i.e. both the attractive interactions between the mAb molecules and substrate surface, and the lateral repulsion between mAb molecules, are reduced.

In the model, ionic strength variations change the electrostatic screening length, the potency of ion binding and lateral repulsion in the surface layer. As ionic strength is increased we find that the decrease in the electrostatic screening length causes the equilibrated value to decrease, but this ceases to change appreciably beyond a relatively low ionic strength $(\gtrsim 25$ $\mathrm{mM}$ ). If ion binding to the $\mathrm{COE}-3$ and $\mathrm{SiO}_{2}$ surfaces is also included, then the decrease in the equilibrated values instead diverges, but not sufficiently to fit the experimental data. This shortcoming is exaggerated at higher protein concentrations, for which there are a decreased number of ions for each protein molecule in the solution. Therefore, ion binding takes a prominent role only in low COE-3 concentration adsorption processes, and changes of the electrostatic screening length take noticeable effect only at low ionic strength. These effects decrease the electrostatic interaction which is repulsive from the FSIP but attractive to the silica. The interaction with the silica is inherently stronger, therefore overall this results in a decrease in the equilibrated values. The final effect of a greater ionic strength is to increase 
the lateral repulsion in the adsorbed layer, and so increase the effective area occupied per adsorbed COE-3 molecule. Only the inclusion of all three effects gives a good fit to the experimental data, as seen in Figure 6(a) where the initial adsorption dynamics was underestimated for the same reason as in Figures 2(a) and 4(a).

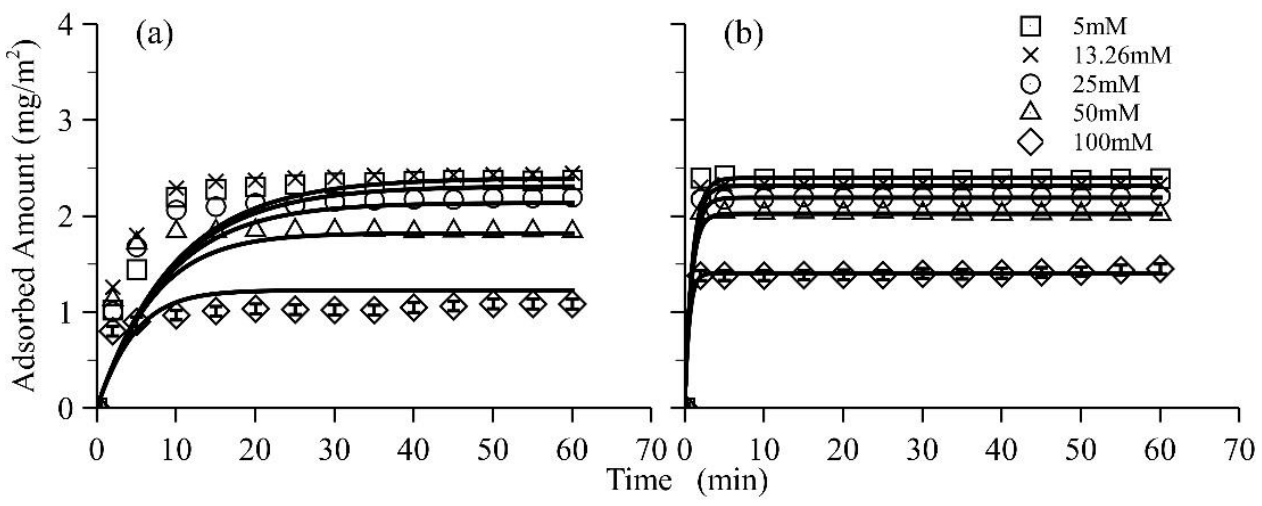

Figure 6. Surface adsorbed amount plotted against time measured by $\mathrm{SE}$ at the $\mathrm{SiO}_{2} /$ water interface to show the effect of His buffer ionic strength (as indicated) for COE-3 concentrations of (a) $0.02 \mathrm{mg} / \mathrm{ml}$ and (b) $0.2 \mathrm{mg} / \mathrm{ml}, \mathrm{pH} 6,20-21^{\circ} \mathrm{C}$. Solid lines represent simulations produced using the model described in the text.

\subsection{Structural conformation of the adsorbed $m A b$ molecules}

As described in Table 2, the thickness $(\tau)$ and surface excess $(\Gamma)$ of the adsorbed COE-3 layers for bulk concentrations $0.002-0.2 \mathrm{mg} / \mathrm{ml}, \mathrm{pH} 5.5$, did not appreciably change, being $50-52 \pm 3 \AA$ and $2.2-2.6 \mathrm{mg} / \mathrm{m}^{2}$, respectively. Given that both Fab and Fc are globular and their short axial lengths are 40-50 $\AA$, these results indicate that the absorbed Fab and Fc were packed as monolayers under these solution conditions. Figure 7 schematically depicts how Fab and Fc segments may adopt their conformational orientations, resulting in a layer of $50 \AA$ thick. Since each $\mathrm{mAb}$ is comprised of $1 \mathrm{Fc}$ and $2 \mathrm{Fabs}$, the packing of these fragments into a monolayer suggests a high degree of structural flexibility. 


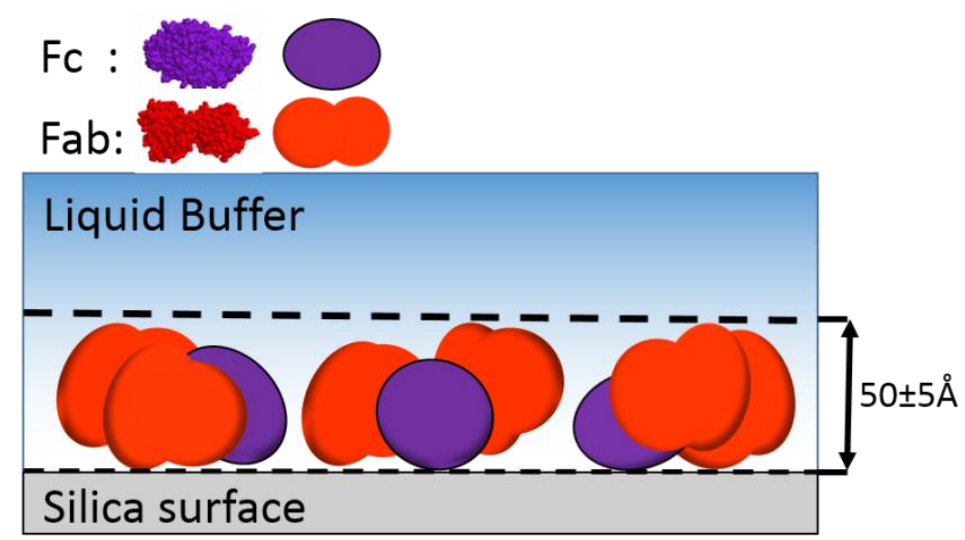

Figure 7. Schematic representation of $\mathrm{COE}-3$ adsorbed at the $\mathrm{SiO}_{2} /$ water interface as measured in the concentration range of $0.02-0.2 \mathrm{mg} / \mathrm{ml}$ at $\mathrm{pH} 5$ where magenta denotes $\mathrm{Fc}$ and red denotes Fab segments.

As discussed above, from the SE data (Figures 2(b)), $2.2 \mathrm{mg} / \mathrm{m}^{2}$ COE-3 was absorbed at equilibrium at the higher bulk concentrations studied, which is equivalent to an area per molecule $\left(A_{p}\right)$ of $11000 \AA^{2}$. For a cross-sectional area of $\sim 4600 \AA^{2}$ for Fc and $\sim 4000 \AA^{2}$ for each Fab, the limiting area per mAb under this type of conformational orientation as depicted in Figure 7 is consistent with the experimental value suggesting that the adsorbed layer was rather densely packed. It should however be noted that as the cross-sectional area was only estimated from the two dimensional lengths based on the crystalline structures of Fc and Fab there must be additional unoccupied space between the segments within the adsorbed layer. The parallel NR measurements at $0.02 \mathrm{mg} / \mathrm{ml}$ COE-3 led to a higher $\Gamma$ of $2.4 \mathrm{mg} / \mathrm{m}^{2}$, equivalent to $A_{p}=10000 \AA^{2}$ (Table 2 and Figure 3a)), as a result of the longer time for adsorption, showing that more $\mathrm{mAb}$ molecules could still be packed into the monolayer under the experimental conditions. It is interesting that this monolayer model is retained under either higher COE-3 concentrations or solution $\mathrm{pH}$, albeit with further increased packing density, e.g. the volume fractions $\left(\phi_{p}\right)$ within the adsorbed layer is $\sim 0.3$ at $\mathrm{pH} 5.5$ but $\sim 0.4-0.5$ at $\mathrm{pH} 9$ for bulk concentrations of $0.02-0.2 \mathrm{mg} / \mathrm{ml}$ (Figure 5(b)). As $\phi_{p}$ reaches 0.5, $\mathrm{mAb} / \mathrm{mAb}$ lateral interactions may incur structural deformation, although the absence of any significant change in layer thickness suggests this is minimal under the conditions studied. Nevertheless, further experiments testing the limit of lateral packing in the monolayer could be warranted in order to reveal whether or not short range attractions between neighboring $\mathrm{mAb}$ molecules also limit their desorption. Since adsorption-induced denaturation is commonly anticipated to occur during industrial process steps, these data highlight that such an event must require either higher bulk concentrations, longer adsorption times or agitation, 
that is, the early adsorption of a mAb molecule at the solid/water interface is not necessarily associated with gross structural deformation.

\subsection{Comparison with adsorption at the air/water interface}

Adsorption of COE-3 on the surface of water has also been undertaken recently under similar solution conditions using a combined study of NR and surface tension. ${ }^{22,23}$ The most noticeable feature was that COE-3 surface adsorption caused only a small decrease in surface tension at bulk concentrations up to $1 \mathrm{mg} / \mathrm{ml}$. This effect could be linked to a high globular stability which is also revealed in the data acquired here and reflected in Figure 7: the layer thicknesses remaining consistent with the short axial lengths of the $\mathrm{Fc}$ and Fab, up to volume fractions $\left(\phi_{p}\right)$ of 0.5 . Although no direct comparison between SE and surface tension measurements can be made, the central time-dependent pattern appears, that is, a fast initial rise in COE-3 adsorption at the interface followed by a slow relaxation process (representing rearrangement of packing between molecules) with the adsorbed amount tending towards plateau at equilibrium. The slow relaxation process is particularly noticeable at the air/water interface and conversely COE-3 tended to adsorb faster and reached a higher adsorbed amount at the solid/water interface. The latter can be accounted for by favorable electrostatic attraction between mAb molecules and the oppositely charged $\mathrm{SiO}_{2}$ surface, as modelled in the simulations. The most noticeable difference in COE-3 adsorption behavior at the air/water and solid/water interfaces was its dependency on the buffer $\mathrm{pH}$; the former changing little while the latter showed a steady rise on moving from mildly acidic to alkaline buffer. This difference can be related to the dominant role played by electrostatic forces between the mAb surface charge and $\mathrm{SiO}_{2}$ substrate. In the context of industrial formulation and fill-finish, changing buffer $\mathrm{pH}$ may offer a route to modulating surface adsorption, at least at very low bulk concentrations of $\mathrm{mAb}$ and assuming such a requirement was identified as necessary during developability assessment.

\subsection{Comparison with the adsorption of other $m A b$ molecules}

Using the same techniques and almost the same solution conditions we have previously studied the $\mathrm{SiO}_{2}$ /water interfacial adsorption of two other IgG1 mAbs. ${ }^{20,21}$ Whilst the exact sequences of these other two mAbs are publically unavailable, Table S2 compares the sequences between COE-3 and a human derived mAb, showing little dissimilarity over the Fc but around $50 \%$ dissimilarity over the Fab. Zhao et al. ${ }^{20}$ showed that the surface adsorption of 
monoclonal anti-human prostate specific antigen (anti-hPSA) at $\mathrm{pH} 7$ increased steadily with bulk concentration from 0.002 to $0.02 \mathrm{mg} / \mathrm{ml} ; \Gamma$ approaching saturation at $3 \mathrm{mg} / \mathrm{m}^{2}$ compared to $2.5 \mathrm{mg} / \mathrm{m}^{2}$ obtained for COE-3 at $0.02 \mathrm{mg} / \mathrm{ml}$ here. However, $\Gamma$ for anti-hPSA increases to $3.6 \mathrm{mg} / \mathrm{m}^{2}$ as the bulk concentration reaches $0.05 \mathrm{mg} / \mathrm{ml}$, while $\Gamma$ for COE-3 reaches a plateau at bulk concentrations above $0.01 \mathrm{mg} / \mathrm{ml}$, which indicates a greater structural stability for COE-3 molecules within the adsorbed monolayer. The adsorption profile of COE-3 at the $\mathrm{SiO}_{2} /$ water interface is more consistent with that of a mAb to the $\alpha$-binding unit of human chorionic gonadotrophin (anti- $\alpha$-hCG), which also plateaued at $0.01 \mathrm{mg} / \mathrm{ml}$ for $\Gamma$ approaching $3 \mathrm{mg} / \mathrm{m}^{2,21}$ These three studies together show that in spite of some differences in their time and concentration-dependent processes, the main features of surface and interfacial adsorption are similar and the final equilibrated adsorbed amounts are generally around 2-3.5 $\mathrm{mg} / \mathrm{m}^{2}$, at these concentrations and buffer conditions tested. The lower saturated adsorbed amount for COE-3 may arise from a more robust globular stability and different charge characteristics. The hypothetical scenario wherein a therapeutic protein is sequestered by interfacial adsorption during i.v. administration from low bulk concentrations using a 'giving set' (i.v. infusion therapy set) therefore needs consideration; this is demonstrated by simulation of COE-3 adsorption from $2 \times 10^{-3} \mathrm{mg} / \mathrm{ml}$ being more accurately modelled from $2 \times 10^{-4} \mathrm{mg} / \mathrm{ml}$ (Figure 2(a)).

The adsorption of mAb molecules onto a support substrate could in principle form different conformational orientations, namely, head-on, tail-on, side-on and flat-on. In reality, it is widely thought that they may adopt a combination of these configurations under a given set of surface and solution conditions. By these designations, the NR measurements at the $\mathrm{SiO}_{2} /$ water interface have revealed the predominantly flat-on conformation in which all 3 fragments ( $\mathrm{Fc}$ and $\mathrm{Fab}$ ) lie parallel to the substrate surface. This basic conformational orientation leads to direct contacts of all fragments with the substrate and between themselves as the packing density goes up. These features are similar for the three mAbs studied, i.e. they all adopt predominantly flat-on conformations with the short axes of Fc and Fab segments lying perpendicular to the $\mathrm{SiO}_{2}$ surface. To gain an indirect understanding of desorption events for individual molecules during an overall adsorption process, it will be necessary in future work to explore how $\mathrm{mAb} / \mathrm{mAb}$ and $\mathrm{mAb} /$ surface contacts affect the extent of structural deformation as a function of packing density.

\subsection{Limitations of the simulation approach}


The simulation based on the DLVO theory relies on the input of the measured data to tune parameters such as the effective radii. This is in contrast to the phenomenological models such as random sequential adsorption (RSA) which calculate the jamming limits of geometries randomly placed onto a planar surface, with the restriction that no overlapping can occur. The jamming limit in each case identifies the maximum fractional coverage that the adsorbing geometry can achieve, which for identical hard disks is $0.547 . .^{33}$ An understanding of why this value is so small can be obtained by the realizationthat, even if the hard discs were placed in a sequence of our choice, we still could not cover the entire surface. This jamming limit is taken into consideration by the effective radii.

Many models are constructed by assuming that adsorption onto the surface is retarded by the interaction with the surface. Often, this manifests itself in the model by means of a retardation factor, which damps the adsorption rate by a constant amount. ${ }^{34}$ In these types of model the retardation factor and an effective protein radius are adjusted until each dataset can be best fitted. The DLVO approach provides a further level of insight by allowing us to identify how each component of the Gibbs potential contributes to an adsorption process. However, this additional insight beyond the retardation factor requires far more than two input values, many of which have to be estimated.

The assumption of hard sphere proteins is one that is only justified for simplicity. Computer simulations into model globular proteins often composed of many connected hard spheres, aid in the discussion on the effect of conformational changes on adsorption processes. ${ }^{35}$ However, these simulations are extremely difficult to apply to specific protein forms, yet this

approach has been carried out using Monte Carlo simulations with some success. ${ }^{36}$ A further related assumption made in this work is that COE-3 has the same charge distribution across its surface, which neglects the fact that Fc and Fab have different charges, size and shape. Thus, these issues must be taken into consideration if the adsorption process must be simulated with accuracy. Given these assumptions and the estimate of the surface tension components of COE-3 made, our model have aimed to aid the experimental data interpretation and understand how protein adsorption is affected by changes to solution properties.

\section{Conclusion}

NR measurements revealed that adsorption of COE-3 at the $\mathrm{SiO}_{2} /$ water interface led to the formation of a monolayer with mAb molecules adsorbed flat-on. The depth sensitivity from NR together with the fast dynamic SE measurements revealed that free surface space was 
initially rapidly occupied by mAb molecules and subsequent adsorption towards equilibrium was not accompanied so much by structural perturbation as by tighter packing rearrangement, especially if accompanied by increasing $\mathrm{pH}$ or simply time. Simulations conducted as described and using full amino acid sequence information enabled the rationalization of the equilibrium adsorption data, most notably the short and long range forces dominating buffer and $\mathrm{pH}$ effects as a function of bulk concentration. Modelling the initial adsorption phase remains challenging since the sparsity of mAb molecules at the surface does not accurately constitute a FSIP as assumed, thereby overestimating the lateral repulsion. In comparison with previously published data for other $\mathrm{mAbs}$ adsorbed at the $\mathrm{SiO}_{2}$ /water interface, the characteristic profile with respect to time, $\mathrm{pH}$ and concentration are largely in agreement, with $\Gamma$ at equilibrium appearing to vary within a defined range according to the individual $\mathrm{mAb}$ conformational stability and $\mathrm{pI}$.

\section{Supporting Information}

The Supporting Information including sequences for the light and heavy chains of the mAb studied here and comparisons against the one with crystalline structures of its fragments, the charge variations of $\mathrm{Fab}, \mathrm{Fc}$ and the whole $\mathrm{COE}-3$ against $\mathrm{pH}$ and the key considerations adopted in the setup of the simulation model under the DLVO framework is available free of charge on the ACS Publications webpage.

\section{Acknowledgements}

We thank funding support from MedImmune Ltd, neutron beam times awarded to undertake this work at ISIS Neutron Facility, Chilton, Didcot, under the support of STFC. ZL acknowledges studentship support from University of Manchester via an Overseas Research Scholarship (ORS) award and a physics research merit award. CS acknowledges a joint PhD studentship from STFC, Unilever and University of Manchester. We also thank EPSRC for support under EP/F062966/1.

\section{References}

(1) KÖhler, G.; Milsein, C. Continuous Cultures of Fused Cells Secreting Antibody of Predefined Specificity. Nature 1975, 256 (5517), 495-497.

(2) Vacchelli, E.; Aranda, F.; Eggermont, A.; Galon, J.; Sautès-Fridman, C.; Zitvogel, L.; Kroemer, G.; Galluzzi, L. Trial Watch. Oncoimmunology 2014, 3 (1), e27048. 
(3) Reichert, J. M. Antibodies to Watch in 2015. MAbs 2015, 7 (1), 1-8.

(4) Krapp, S.; Mimura, Y.; Jefferis, R.; Huber, R.; Sondermann, P. Structural Analysis of Human IgG-Fc Glycoforms Reveals a Correlation Between Glycosylation and Structural Integrity. J. Mol. Biol. 2003, 325 (5), 979-989.

(5) Tamada, T.; Shinmi, D.; Ikeda, M.; Yonezawa, Y.; Kataoka, S.; Kuroki, R.; Mori, E.; Motoki, K. TRAIL-R2 Superoligomerization Induced by Human Monoclonal Agonistic Antibody KMTR2. Sci. Rep. 2016, 5 (1), 17936.

(6) Couston, R. G.; Skoda, M. W.; Uddin, S.; van der Walle, C. F. Adsorption Behavior of a Human Monoclonal Antibody at Hydrophilic and Hydrophobic Surfaces. MAbs 2013, 5 (1), 126-139.

(7) Yoo, J.-W.; Irvine, D. J.; Discher, D. E.; Mitragotri, S. Bio-Inspired, Bioengineered and Biomimetic Drug Delivery Carriers. Nat. Rev. Drug Discov. 2011, 10 (7), 521535.

(8) Mazor, Y.; Hansen, A.; Yang, C.; Chowdhury, P. S.; Wang, J.; Stephens, G.; Wu, H.; Dall'Acqua, W. F. Insights into the Molecular Basis of a Bispecific Antibody's Target Selectivity. MAbs 2015, 7 (3), 461-469.

(9) Perchiacca, J. M.; Ladiwala, A. R. A.; Bhattacharya, M.; Tessier, P. M. AggregationResistant Domain Antibodies Engineered with Charged Mutations near the Edges of the Complementarity-Determining Regions. Protein Eng. Des. Sel. 2012, 25 (10), 591602.

(10) Perevozchikova, T.; Nanda, H.; Nesta, D. P.; Roberts, C. J. Protein Adsorption, Desorption, and Aggregation Mediated by Solid-Liquid Interfaces. J. Pharm. Sci. 2015, 104 (6), 1946-1959.

(11) Britt, K. A.; Schwartz, D. K.; Wurth, C.; Mahler, H.; Carpenter, J. F.; Randolph, T. W. Excipient Effects on Humanized Monoclonal Antibody Interactions with Silicone Oil Emulsions. J. Pharm. Sci. 2012, 101 (12), 4419-4432.

(12) Hoehne, M.; Samuel, F.; Dong, A.; Wurth, C.; Mahler, H.-C.; Carpenter, J. F.; Randolph, T. W. Adsorption of Monoclonal Antibodies to Glass Microparticles. J. Pharm. Sci. 2011, 100 (1), 123-132.

(13) Kapp, S. J.; Larsson, I.; van De Weert, M.; Cárdenas, M.; Jorgensen, L. Competitive Adsorption of Monoclonal Antibodies and Nonionic Surfactants at Solid Hydrophobic Surfaces. J. Pharm. Sci. 2015, 104 (2), 593-601.

(14) Leiske, D. L.; Shieh, I. C.; Tse, M. L. A Method To Measure Protein Unfolding at an Air-Liquid Interface. Langmuir 2016, 32 (39), 9930-9937. 
(15) Oom, A.; Poggi, M.; Wikström, J.; Sukumar, M. Surface Interactions of Monoclonal Antibodies Characterized by Quartz Crystal Microbalance with Dissipation: Impact of Hydrophobicity and Protein Self-Interactions. J. Pharm. Sci. 2012, 101 (2), 519-529.

(16) Härtl, E.; Dixit, N.; Besheer, A.; Kalonia, D.; Winter, G. Weak Antibody-cyclodextrin Interactions Determined by Quartz Crystal Microbalance and Dynamic/static Light Scattering. Eur. J. Pharm. Biopharm. 2013, 85 (3), 781-789.

(17) Lu, J.R.; Zhao, X.B.; YASEEN, M. Protein Adsorption Studied by Neutron Reflection. Curr. Opin. Colloid Interface Sci. 2007, 12 (1), 9-16.

(18) Lu, J. R.; Perumal, S.; Zhao, X.B.; Miano, F.; Enea, V.; Heenan, R. R.; Penfold, J. Surface-Induced Unfolding of Human Lactoferrin. Langmuir 2005, 21 (8), 3354-3361.

(19) Zhao, X.B.; Pan, F.; Garcia-Gancedo, L.; Flewitt, A. J.; Ashley, G. M.; Luo, J.; Lu, J. R. Interfacial Recognition of Human Prostate-Specific Antigen by Immobilized Monoclonal Antibody: Effects of Solution Conditions and Surface Chemistry. J. R. Soc. Interface 2012, 9 (75), 2457-2467.

(20) Zhao, X.B.; Pan, F.; Cowsill, B.; Lu, J. R.; Garcia-Gancedo, L.; Flewitt, A. J.; Ashley, G. M.; Luo, J. Interfacial Immobilization of Monoclonal Antibody and Detection of Human Prostate-Specific Antigen. Langmuir 2011, 27 (12), 7654-7662.

(21) Xu, H.; Zhao, X.B.; Grant, C.; Lu, J. R.; Williams, D. E.; Penfold, J. Orientation of a Monoclonal Antibody Adsorbed at the Solid/Solution Interface: A Combined Study Using Atomic Force Microscopy and Neutron Reflectivity. Langmuir 2006, 22 (14), 6313-6320.

(22) Li, Z.; Li, R.; Smith, C.; Pan, F.; Campana, M.; Webster, J. R. P.; van der Walle, C. F.; Uddin, S.; Bishop, S. M.; Narwal, R.; Warwicker, J.; Lu, J. R. Neutron Reflection Study of Surface Adsorption of Fc, Fab, and the Whole mAb. ACS Appl. Mater. Interfaces 2017, 9 (27), 23202-23211.

(23) Smith, C.; Li, Z.; Holman, R.; Pan, F.; Campbell, R. A.; Campana, M.; Li, P.; Webster, J. R. P.; Bishop, S.; Narwal, R.; Uddin, S.; van der Walle, C. F.; Lu, J. R. Antibody Adsorption on the Surface of Water Studied by Neutron Reflection. MAbs 2017, 9 (3), $466-475$.

(24) Roberts, D.; Keeling, R.; Tracka, M.; van der Walle, C. F.; Uddin, S.; Warwicker, J.; Curtis, R. The Role of Electrostatics in Protein-Protein Interactions of a Monoclonal Antibody. Mol. Pharm. 2014, 11 (7), 2475-2489.

(25) Pan, F.; Zhao, X.B.; Perumal, S.; Waigh, T. A.; Lu, J. R.; Webster, J. R. P. Interfacial Dynamic Adsorption and Structure of Molecular Layers of Peptide Surfactants. 
Langmuir 2010, 26 (8), 5690-5696.

(26) De Feijter, J. A.; Benjamins, J.; Veer, F. A. Ellipsometry as a Tool to Study the Adsorption Behavior of Synthetic and Biopolymers at the Air-Water Interface. Biopolymers 1978, 17 (7), 1759-1772.

(27) Cowsill, B. J.; Zhao, X.B.; Waigh, T. A.; Eapen, S.; Davies, R.; Laux, V.; Haertlein, M.; Forsyth, V. T.; Lu, J. R. Interfacial Structure of Immobilized Antibodies and Perdeuterated HSA in Model Pregnancy Tests Measured with Neutron Reflectivity. Langmuir 2014, 30 (20), 5880-5887.

(28) Su, T. J.; Lu, J. R.; Thomas, R. K.; Cui, Z. F.; Penfold, J. The Adsorption of Lysozyme at the Silica-Water Interface: A Neutron Reflection Study. J. Colloid Interface Sci. 1998, 203 (2), 419-429.

(29) Cacace, M. G.; Landau, E. M.; Ramsden, J. J. The Hofmeister Series: Salt and Solvent Effects on Interfacial Phenomena. Q. Rev. Biophys. 1997, 30 (3), S0033583597003363.

(30) Cadilhe, A.; Araújo, N. A. M.; Privman, V. Random Sequential Adsorption: From Continuum to Lattice and Pre-Patterned Substrates. J. Phys. Condens. Matter 2007, 19 (6), 65124.

(31) Adamczyk, Z.; Weroński, P. Application of the DLVO Theory for Particle Deposition Problems. Adv. Colloid Interface Sci. 1999, 83 (1-3), 137-226.

(32) Jenkins, F.A.; White, H. . Fundamentals of Optics, 4th Ed.; McGraw-Hill, 1981.

(33) Talbot, J.; Tarjus, G.; Van Tassel, P. R.; Viot, P. From Car Parking to Protein Adsorption: An Overview of Sequential Adsorption Processes. Colloids Surfaces A Physicochem. Eng. Asp. 2000, 165 (1-3), 287-324.

(34) Buijs, J.; van den Berg, P. A. W.; Lichtenbelt, J. W. T.; Norde, W.; Lyklema, J. Adsorption Dynamics of IgG and Its F(ab')2and Fc Fragments Studied by Reflectometry. J. Colloid Interface Sci. 1996, 178 (2), 594-605.

(35) Euston, S. R.; Naser, M. A. Simulating the Equation of State of Model Globular Proteins Adsorbed at a Surface. Langmuir 2005, 21 (9), 4227-4235.

(36) Zhou, J.; Chen, S.; Jiang, S. Orientation of Adsorbed Antibodies on Charged Surfaces by Computer Simulation Based on a United-Residue Model. Langmuir 2003, 19 (8), 3472-3478. 
ToC:

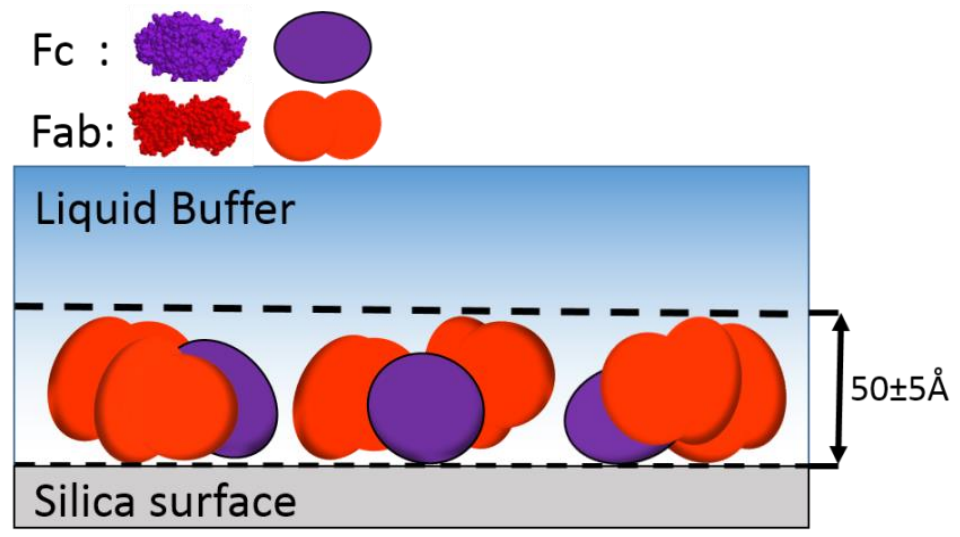




\section{Support Information}

\section{Interfacial Adsorption of Monoclonal Antibody COE-3 at the Solid/Water Interface}

Fang Pan $^{1}$, Zongyi $\mathrm{Li}^{1}$, Thomas Leyshon ${ }^{1}$, Dominic Rouse ${ }^{1}$, Ruiheng $\mathrm{Li}^{1}$, Charles Smith ${ }^{1}$, Mario Campana ${ }^{2}$, John R P Webster ${ }^{2}$, Steven M. Bishop ${ }^{4}$, Rojaramani Narwal ${ }^{4}$, Christopher F van der Walle ${ }^{3}$, Jim Warwicker ${ }^{5}$, Jian Ren Lu* ${ }^{1}$

${ }^{1}$ Biological Physics Laboratory, School of Physics and Astronomy, University of Manchester, Oxford Road, Schuster Building, Manchester M13 9PL, UK.

${ }^{2}$ ISIS Neutron Facility, STFC, Chilton, Didcot OX11 0QZ, UK.

${ }^{3}$ Formulation Sciences, MedImmune Ltd, Sir Aaron Klug Building, Granta Park, Cambridge CB21 6GH, UK

${ }^{4}$ Formulation Sciences, MedImmune LLC, Gaithersburg, MD 20878, USA.

${ }^{5}$ School of Chemistry, University of Manchester, Oxford Road, Chemistry Building, Manchester M13 9PL, UK.

*Corresponding author: Jian R Lu (email: j.lu@ manchester.ac.uk; Tel: +44 161 2003926)

FP and ZL made equal contributions 


\section{Section S1: Surface and interfacial measurements of mAb adsorption and physical}

\section{properties of $\mathbf{m A b}$}

Figure S1. Charge distribution as a function of $\mathrm{pH}$ for Fab and $\mathrm{Fc}$ and the whole COE-3 (1/3 contribution from $1 \mathrm{Fc}$ and $2 \mathrm{Fabs}$ ) as calculated from the heavy chain sequences only.

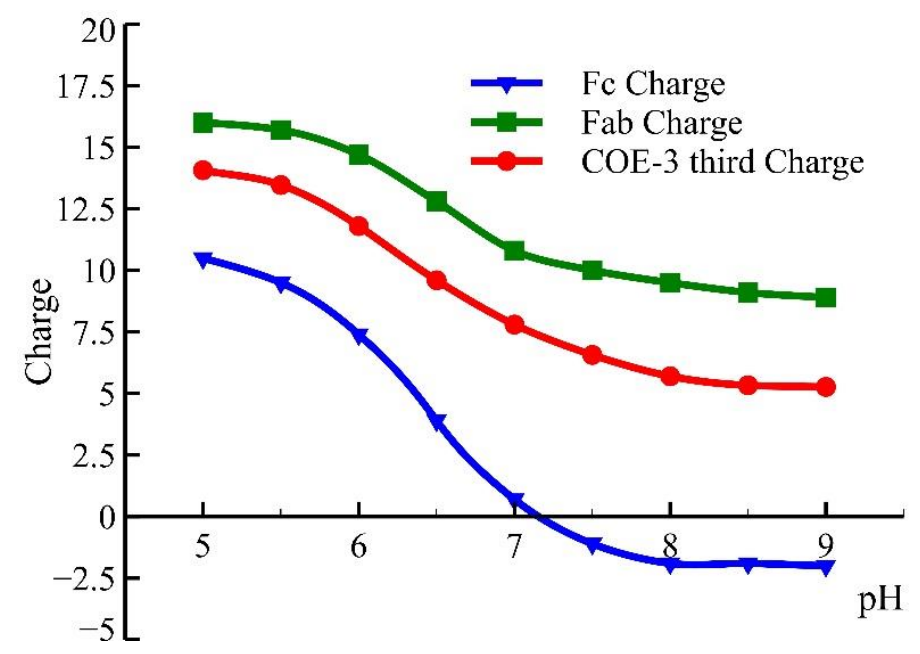

These charge variations against $\mathrm{pH}$ as calculated from the constituent amino acids are different from the measured IP values from real experimental measurements due to the ignorance of charges on sugar groups and associations with ions from bulk solution. 
Figure S2. Ellipsometric scans of the amplitude component $\Psi$ (a) and the phase difference $\Delta$ (b) against wavelength measured at the $\mathrm{SiO}_{2}$ /water interface after 5 min of adsorption under COE-3 concentrations of $0.005,0.02$ and $0.1 \mathrm{mg} / \mathrm{ml}$ in $25 \mathrm{mM}$ His buffer, $\mathrm{pH}$ 5.5. The continuous lines were best uniform layer fits with the adsorbed amount plotted in Figure 2(a).
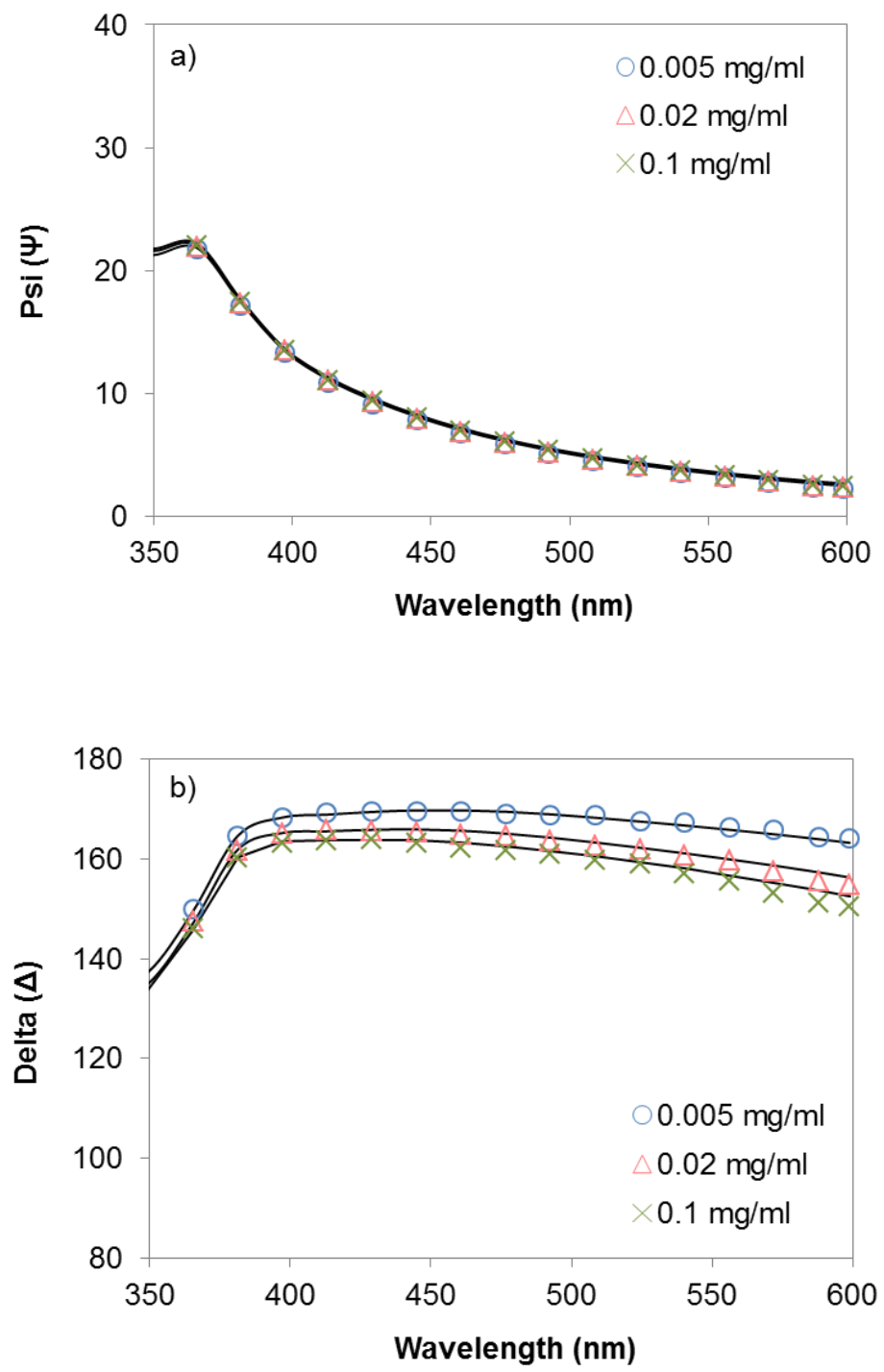
Table S1. Key sequence information for COE-3

Table S1A. The antibody molecule is comprised of 2 identical light and heavy polypeptide chains.

The sequence of the Light Chain:

DIQMTQSPSSLSASVGDRVTITCRASQSISSYLNWYQQKPGKAPKLLIYAASSLQSGV PSRFSGSGSGTDFTLTISSLQPEDFATYYCQQSYSTPLTFGGGSKVEIKRTVAAPSVFIF PPSDEQLKSGTASVVCLLNNFYPREAKVQWKVDNALQSGNSQESVTEQDSKDSTYS LSSTLTLSKADYEKHKVYACEVTHQGLSSPVTKSFNRGEC

The sequence of the Heavy Chain:

QVNLRESGGGLVQPGGSLRLSCAASGFTFGSYAMSWVRQAPGKGLEWVSAISGSGG STYYADSVKGRFTISRDNSKNSLYLQMNSLRAEDTAVYYCARRSIYGGNYYFDYWG RGTLVTVSSASTKGPSVFPLAPSSKSTSGGTAALGCLVKDYFPEPVTVSWNSGALTSG VHTFPAVLQSSGLYSLSSVVTVPSSSLGTQTYICNVNHKPSNTKVDKKVEPKSCDKT HTCPPCPAPELLGGPSVFLFPPKPKDTLMISRTPEVTCVVVDVSHEDPEVKFNWYVD GVEVHNAKTKPREEQYNSTYRVVSVLTVLHQDWLNGKEYKCKVSNKALPAPIEKTI SKAKGQPREPQVYTLPPSRDELTKNQVSLTCLVKGFYPSDIAVEWESNGQPENNYKT TPPVLDSDGSFFLYSKLTVDKSRWQQGNVFSCSVMHEALHNHYTQKSLSLSPGK

The two constant domains $\left(\mathrm{C}_{\mathrm{H}} \gamma 3\right.$ and $\mathrm{C}_{\mathrm{H}} \gamma 2$ in blue) of each heavy chain form the Fc, which is then dimeric. The $\mathrm{C}_{\mathrm{H}} \gamma 1$ and variable domain $\left(\mathrm{V}_{\mathrm{H}}\right)$ of the heavy chain, both in red text, together with the light chain $\left(\mathrm{C}_{\mathrm{L}} \kappa / \lambda\right.$ and $\mathrm{V}_{\mathrm{L}}$ domains) form each of the two Fab arms.

The sequences were entered into the Biomolecular Scattering Length Density Calculator (http://psldc.isis.rl.ac.uk/Psldc/) and the influence of the isotopic contrast of water was set accordingly to obtain the respective scattering lengths (SL) and scattering length density (SLD) under $\mathrm{D}_{2} \mathrm{O}$, with the results shown below.

TableS1B. Key parameters used for $\mathrm{D}_{2} \mathrm{O}$ and COE-3

\begin{tabular}{|l|l|l|l|}
\hline Molecular structure & SL $\times 10^{5} / \AA$ & ${\text { Volume } / \AA^{3}}^{3}$ & SLD $\times 10^{6} / \AA^{-2}$ \\
\hline $\mathrm{D}_{2} \mathrm{O}$ & 19.14 & 30 & 6.35 \\
\hline $\mathrm{COE}-3$ & 57648 & 171740 & 3.36 \\
\hline
\end{tabular}

The molecular weight of COE-3 is approximately 144,750 in $\mathrm{H}_{2} \mathrm{O}$. 
Tables S2A. Amino acid sequence comparison between Fc of COE-03 and Fc of 1HZH (Protein Data Bank ID code, reference below).

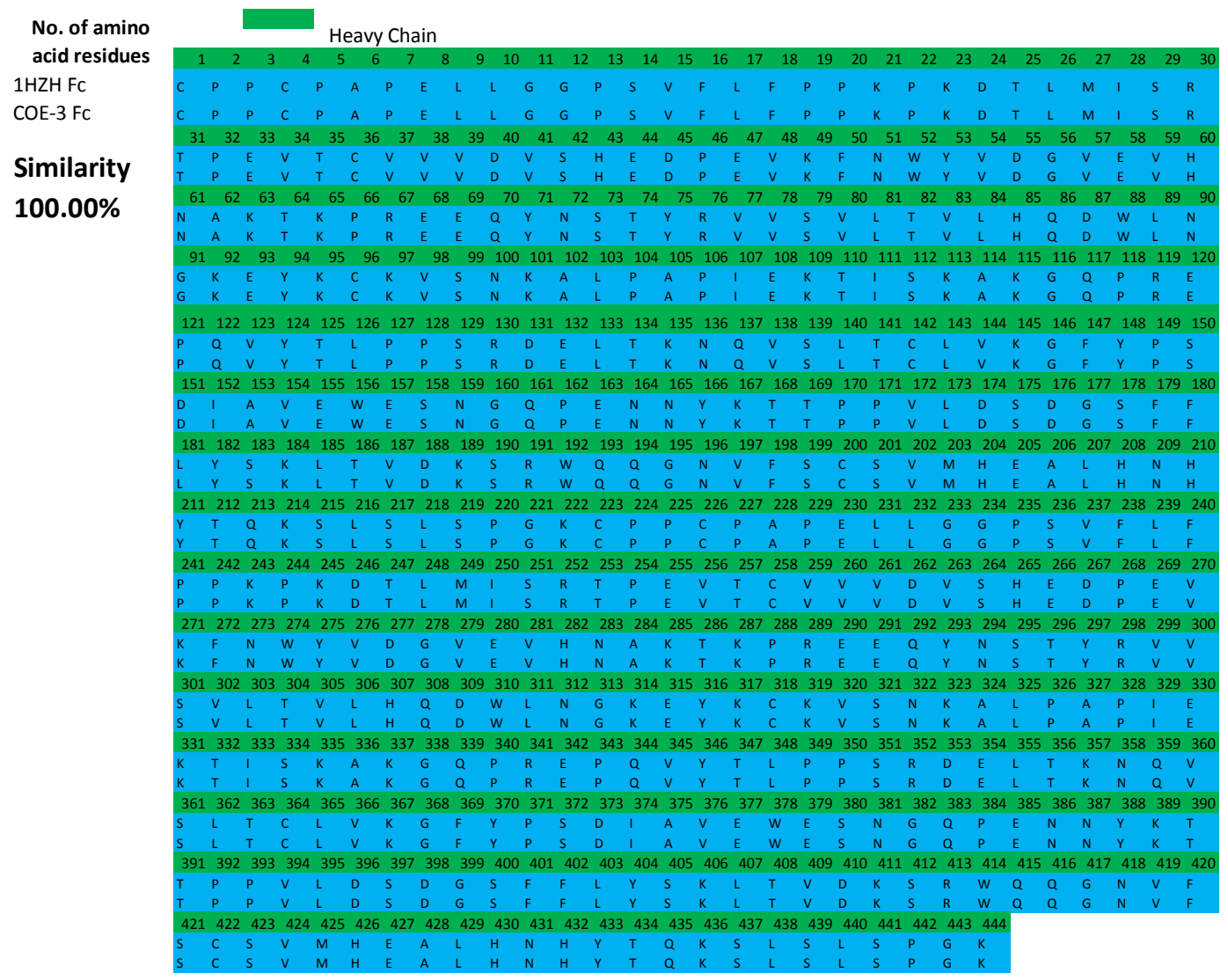

The $1 \mathrm{HZH}$ Fc sequence was from Saphire et al. ${ }^{\mathrm{S} 1}$ at the end of Support Information. 
Table S2B. Amino acid sequence comparing between COE-3 Fab and Fab of 1HZH.

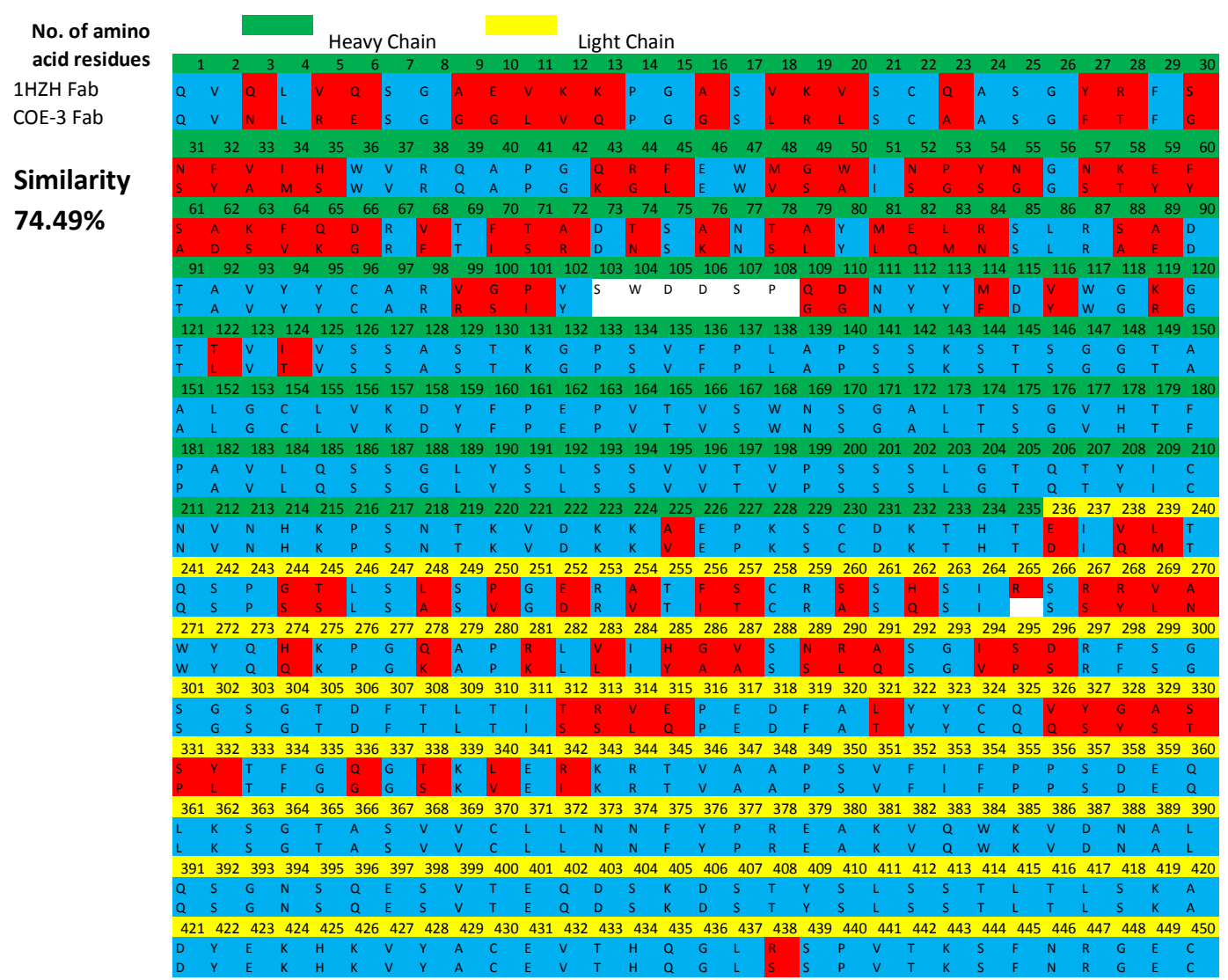

The 1HZH Fab sequence was from Sapphire et $\mathrm{al}^{\mathrm{S} 1}$ at the end of Support Information. 
Figure S3. The change in surface tension when 500 ppm COE-3 was added to histidine buffer $25 \mathrm{mM}$ at $\mathrm{pH} 6$.

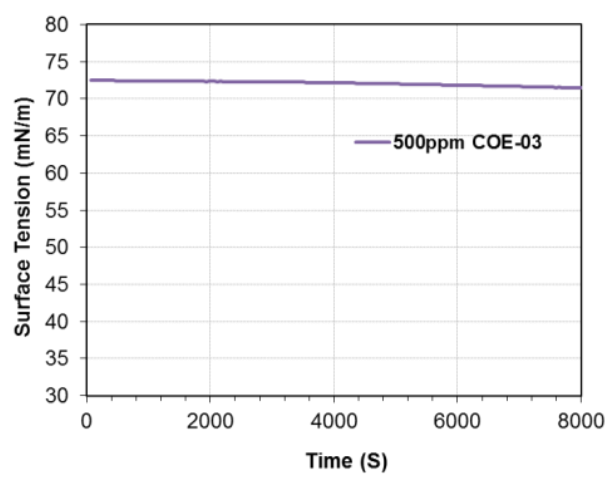

The surface tension shows little change from $72.8 \mathrm{mN} / \mathrm{m}$, suggesting COE-3 has a surface tension similar to water, especially over the duration of an adsorption experiment. 


\section{Section S2A：DLVO theory}

The specific forms of the Gibbs potentials of the LW and DA forces between a hard sphere of radius $R$ and a semi-infinite plane are

$$
\mathrm{G}_{\mathrm{i} 2 \mathrm{j}}^{\mathrm{lw}}(\mathrm{z})=2 \pi \mathrm{l}_{0}^{2} \mathrm{RG}_{\mathrm{i} 2 \mathrm{j}}^{\mathrm{lw} \|} / \mathrm{z}
$$

and

$$
\mathrm{G}_{\mathrm{i} 2 \mathrm{j}}^{\mathrm{da}}(\mathrm{z})=2 \pi \chi R \mathrm{RG}_{\mathrm{i} 2 \mathrm{j}}^{\mathrm{da} \|} \exp \left[\frac{1}{\chi}\left(l_{0}-\mathrm{z}\right)\right]
$$

where $\mathrm{G}^{\mathrm{x} \|_{\mathrm{i} 2 \mathrm{j}}}$ are the Gibbs potentials for a force $x$ between two semi-infinite planes separated by the equilibrium distance $l_{0}=0.157 \mathrm{~nm} .{ }^{\mathrm{S} 2}$ The remaining parts of the equations convert this interaction to be between a semi-infinite plane and a hard sphere a distance $z$ away. ${ }^{\mathrm{S} 3} \mathrm{In}$ Equ. S2, $\chi$ is the DA interaction decay length whose precise value varies but can be taken to be $1 \mathrm{~nm} .{ }^{\mathrm{S} 2}$ As indicated in the main text, $\mathrm{G}^{\mathrm{x}} \|_{\mathrm{i} 2 \mathrm{j}}$ are functions of the surface tensions of the silica (1), liquid medium (2) and COE-3 (3) when the force $x$ is LW or DA. The general forms are given by the Dupré equations, which are

$$
\mathrm{G}_{123}^{\mathrm{x} \|}=\gamma_{13}^{\mathrm{x}}-\gamma_{12}^{\mathrm{x}}-\gamma_{32}^{\mathrm{x}}
$$

for silica - water - COE-3 interactions, and

$$
\mathrm{G}_{323}^{\mathrm{x} \|}=-2 \gamma_{23}^{\mathrm{x}}
$$

for COE-3 - water - COE-3 interactions, where $\gamma^{x}{ }_{i j}$ are functions of the individual materials surface tensions, with a form dependent on the interaction type. ${ }^{\mathrm{S} 4}$ The total surface tension, $\mathrm{Y}$ of a material $i$ can be decomposed into three components. These are the LW component, $\gamma^{l w}{ }_{i}$ and the donor and acceptor components, $\gamma_{i}^{d}$ and $\gamma_{i}^{a}$ respectively, which sum as

$$
Y_{i}=\gamma_{i}^{l w}+2 \sqrt{\gamma_{i}^{d} \gamma_{i}^{a}}
$$

The combination rules for LW and DA interactions are 


$$
\gamma_{\mathrm{ij}}^{\mathrm{lw}}=\left(\sqrt{\gamma_{\mathrm{i}}^{\mathrm{lw}}}-\sqrt{\gamma_{\mathrm{j}}^{\mathrm{lw}}}\right)^{2}
$$

and

$$
\gamma_{\mathrm{ij}}^{\mathrm{da}}=2\left(\sqrt{\gamma_{\mathrm{i}}^{\mathrm{d}}}-\sqrt{\gamma_{\mathrm{j}}^{\mathrm{d}}}\right)\left(-\sqrt{\gamma_{\mathrm{j}}^{\mathrm{a}}}\right)
$$

respectively. ${ }^{\text {S2 }}$ Finally, the EL contribution depends instead on the surface potentials of the two interacting bodies, $\psi_{\mathrm{i}}$ and $\psi_{\mathrm{j}}$ via

$$
\mathrm{G}_{\mathrm{i} 2 \mathrm{j}}^{\mathrm{el}}(\mathrm{z})=4 \pi \mathrm{R} \epsilon_{0} \epsilon_{\mathrm{r}} \psi_{\mathrm{i}} \psi_{\mathrm{j}} \ln [1+\exp (-\kappa \mathrm{z})]
$$

where $\epsilon_{O}\left(\epsilon_{r}\right)$ is the vacuum (relative) permittivity, and

$$
\kappa=\left(\frac{2000 \mathrm{e}^{2} \mathrm{~N}_{\mathrm{A}} \mathrm{I}}{\epsilon_{0} \epsilon_{\mathrm{r}} \mathrm{k}_{\mathrm{B}} \mathrm{T}}\right)^{0.5}
$$

is the inverse of the Debye screening length in $\mathrm{m}^{-1}$ where $k_{B}$ is the Boltzmann constant, $e$ is the electron charge, $N_{A}$ is Avogadro's number, $T$ is the solution temperature and $I$ is the ionic strength of the liquid medium in molars. ${ }^{\mathrm{S} 3, \mathrm{~S} 5}$ The surface potential for amphoteric surfaces such as silica with isoelectric point $p H_{0}$ and ionization constant $\Delta p K$ is found from

$$
\frac{1}{\alpha} \sinh \left(\frac{y}{2}\right)=\frac{\delta \sinh (2.303 \Delta \mathrm{pH}-y)}{1+\delta \cosh (2.303 \Delta \mathrm{pH}-y)}
$$

where $\delta=2 \times 10^{-\Delta \mathrm{pK} / 2}, \Delta \mathrm{pH}=\mathrm{pH}_{0}-\mathrm{pH}$ where $\mathrm{pH}$ is that of the liquid medium and $\alpha=\frac{\mathrm{N}_{\mathrm{s}} \kappa}{4 \mathrm{~N}_{\mathrm{A}} \mathrm{I}}$ where $N_{s}$ is the number of sites on silica, commonly taken as $8 \mathrm{~nm}^{-2}$ and $y=\frac{\psi_{1} \mathrm{e}}{\mathrm{k}_{\mathrm{B}} \mathrm{T}}$ is the dimensionless potential. ${ }^{\mathrm{S} 3, \mathrm{~S} 6}$ The $\Delta p K$ value used for silica is $7 .^{\mathrm{S} 3}$ The presence of the amphoteric surface modifies the $\mathrm{pH}$ of the solution in its immediate vicinity to

$$
\mathrm{pH}_{\mathrm{s}}=\mathrm{pH}+\frac{y}{2.303}
$$

which is the $\mathrm{pH}$ that the adsorbed protein layer resides within. ${ }^{\mathrm{S} 3}$ The surface potential of the protein, $\psi_{3}$ is often taken to be equal to its zeta potential, $\zeta$. This is a measurement of the potential due to the charge of the protein as well as any buffer ions within the slipping plane, 
located at approximately $4 \AA .{ }^{S 2}$ The assumption that the surface potential can be taken as the zeta potential is accurate when the protein radius and Debye screening length are large compared to the distance to the slipping plane. ${ }^{\mathrm{S} 2}$ The relation between zeta potential and surface charges, Q is approximately

$$
Q=2 \frac{\mathrm{eR}^{2} \kappa}{l_{\mathrm{B}}} \sinh \left(\frac{\tilde{\zeta}}{2}\right)\left[1+\frac{2}{(\kappa \mathrm{R}) \cosh ^{2}(\tilde{\zeta} / 4)}+\frac{8 \log \left(\cosh ^{2}(\tilde{\zeta} / 4)\right)}{(\kappa \mathrm{R})^{2} \sinh (\tilde{\zeta} / 2)}\right]^{0.5}
$$

where $\tilde{\zeta}=\frac{\zeta \mathrm{e}}{\mathrm{k}_{\mathrm{B}} \mathrm{T}}$ is the dimensionless zeta potential and $l_{\mathrm{B}}=\frac{\mathrm{e}^{2}}{4 \pi \epsilon_{0} \epsilon_{\mathrm{r}} \mathrm{k}_{\mathrm{B}}^{\mathrm{T}}}$ is the Bjerrum length. ${ }^{\mathrm{S} 7}$ As indicated in the main text Equ. S12 is for a monovalent buffer but was used for simplicity. ${ }^{\mathrm{S} 7}$ Figure S4 shows example plots of silica - protein (a), and protein - protein (b) interactions. Note that in our model we assume that the proteins cannot become bound in the infinite well, as the barrier preventing this is so large. Further justification of this assumption is that the infinite well is inaccessible if the Born repulsion limit is accounted for. This is a limit on the closest approach of any two bodies, enforced by the Lennard-Jones interaction, and has the value $0.136 \mathrm{~nm} .^{\mathrm{S} 2}$
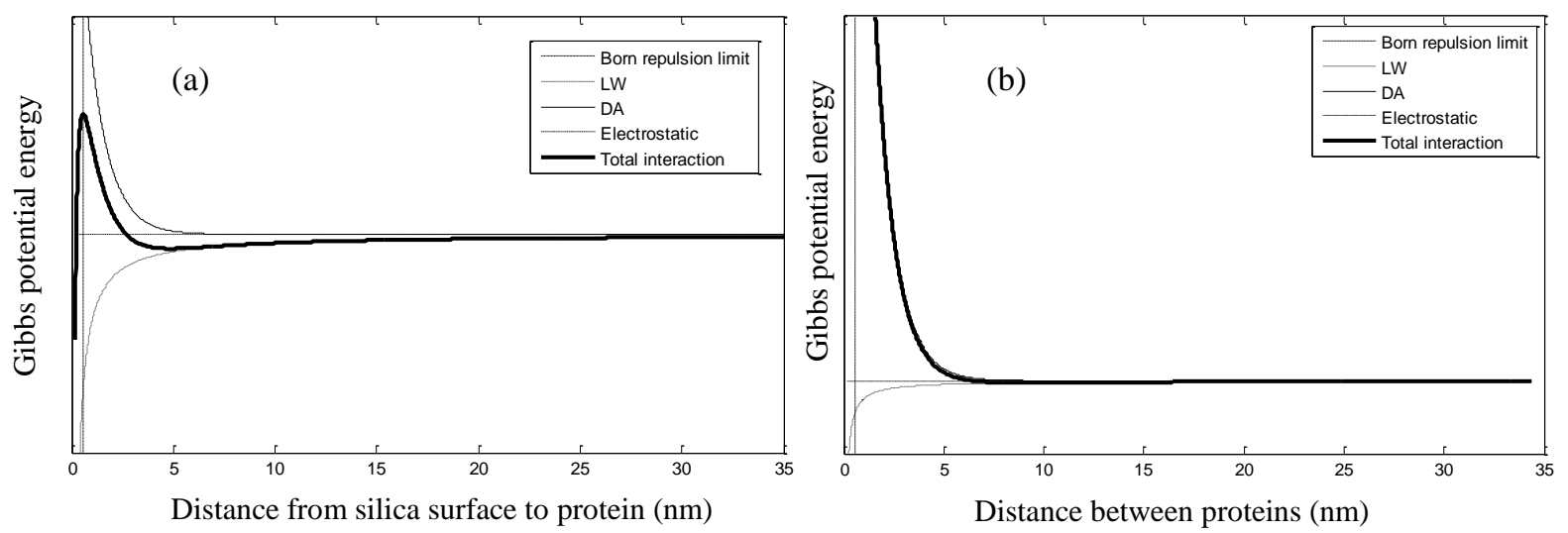

Figure S4. Gibbs distribution plots. (a) Example plot of Gibbs interaction between a protein in solution and the semi-infinite silica plane. Proteins cannot absorb into the infinite well at zero distance from the plane, but can adsorb into the finite minimum. (b) Example plot of Gibbs interaction between the protein FSIP and a protein in solution. Here the proteins are repulsive, with no minimum forming.

\section{Section S2B: Protein-protein interaction map}

The interactions between proteins can either be repulsive, attractive or long-range attraction with short-range repulsion (type-2 attraction). This depends on the surface tensions of the 
protein in the solution. The LW component of the Gibbs energy change is always negative (or zero) for COE-3-water-COE-3 interactions, but the DA contribution can be either negative or positive. ${ }^{\mathrm{S} 2}$ When the DA component is positive this produces overall attraction, with a negative energy change on the protein association. The sign of the DA force is decided by the sign of the factor $G^{x \|}{ }_{i 2 j}$ and therefore entirely by the surface tensions. So, the condition separating attraction from repulsion (and type-2 attraction), is

$$
G_{323}^{d a \|}=-2 \gamma_{23}^{d a}=-4\left(\sqrt{\gamma_{2}^{\mathrm{d}}}-\sqrt{\gamma_{3}^{\mathrm{d}}}\right)\left(\sqrt{\gamma_{2}^{\mathrm{a}}}-\sqrt{\gamma_{3}^{\mathrm{a}}}\right)\left\{\begin{array}{l}
>0, \text { for repulsion } \\
<0, \text { for attraction }
\end{array}\right.
$$

which stems from the need for a positive contribution to the Gibbs energy to counteract the LW component and so creates an energy barrier, and hence a repulsion. Of course, for this to be true, the magnitude of DA component must be larger than the LW at some separation. From Equ. $S 1$ and $S 2$ we can see that even for $\left|G^{\operatorname{lw|}}{ }_{323}\right|=\left|G^{\text {da } \|_{323}}\right|$, then at the equilibrium separation the DA component is about 10 times the magnitude. It is therefore safe to assume that the DA component prevails over the $\mathrm{LW}$ at some separation. If $\mathrm{G}^{\text {da } \|_{323}}>0$, interactions only have the potential to be completely repulsive if an additional condition is met, this being $\left|G^{\text {lw||}}{ }_{323}\right|<\left|G^{\text {da||}}{ }_{323}\right|$. If this is not satisfied then at large distances the proteins will exhibit type-2 attraction, only repelling when close. This condition can be seen by examining the condition for large distance repulsion, i.e. that the gradient of the combined LW and DA protein-protein Gibbs energies are negative at large distances. From Equ. S1 and S2, if we make the approximation that $\exp \left[\frac{\mathrm{l}}{\chi}\right] \approx 1$, we find that for $\mathrm{G}^{\mathrm{da} \|_{323}}>0$

$$
\frac{\mathrm{d}\left(\mathrm{G}_{323}^{\mathrm{da}}+\mathrm{G}_{323}^{\mathrm{lw}}\right)}{\mathrm{dz}} \approx \frac{\mathrm{l}_{0}^{2}}{\mathrm{z}^{2}}\left|\mathrm{G}_{323}^{l w \|}\right|-\exp \left[-\frac{\mathrm{z}}{\chi}\right]\left|\mathrm{G}_{323}^{d a \|}\right|
$$

As $\mathrm{z}$ becomes large, the only possibility for this gradient to become negative occurs if the prior stated condition is satisfied. Therefore, the second condition for (complete) repulsion is

$$
\left|\sqrt{\gamma_{3}^{d}}-\sqrt{\gamma_{2}^{d}}\right|>\frac{\left(\sqrt{\gamma_{2}^{\mathrm{lw}}}-\sqrt{\gamma_{3}^{\mathrm{lw}}}\right)^{2}}{2\left|\sqrt{\gamma_{2}^{a}}-\sqrt{\gamma_{3}^{a}}\right|}
$$

The LW Gibbs potential energy component is always negative. Ignoring electrostatic contributions (as these do not depend on surface tension), this implies that the DA component 
between the silica and protein must be positive in order to produce a minimum in the initial Gibbs distribution. The sign of this interaction between the silica layer and COE-3 is determined by $\mathrm{G}^{\mathrm{da} \|_{123}}$, which leads to the adsorption condition

$$
\sqrt{\gamma_{3}^{\mathrm{d}}}>-\sqrt{\gamma_{3}^{\mathrm{a}}} \frac{\sqrt{\gamma_{2}^{\mathrm{d}}}-\sqrt{\gamma_{1}^{\mathrm{d}}}}{\sqrt{\gamma_{2}^{\mathrm{a}}}-\sqrt{\gamma_{1}^{\mathrm{a}}}}+\frac{2 \sqrt{\gamma_{2}^{\mathrm{a}} \gamma_{2}^{\mathrm{d}}}-\sqrt{\gamma_{1}^{\mathrm{a}} \gamma_{2}^{\mathrm{d}}}-\sqrt{\gamma_{1}^{\mathrm{d}} \gamma_{2}^{\mathrm{a}}}}{\sqrt{\gamma_{2}^{\mathrm{a}}}-\sqrt{\gamma_{1}^{\mathrm{a}}}}
$$

Figure S5 below shows the protein - protein interaction map used to determine suitable surface tension parameters.

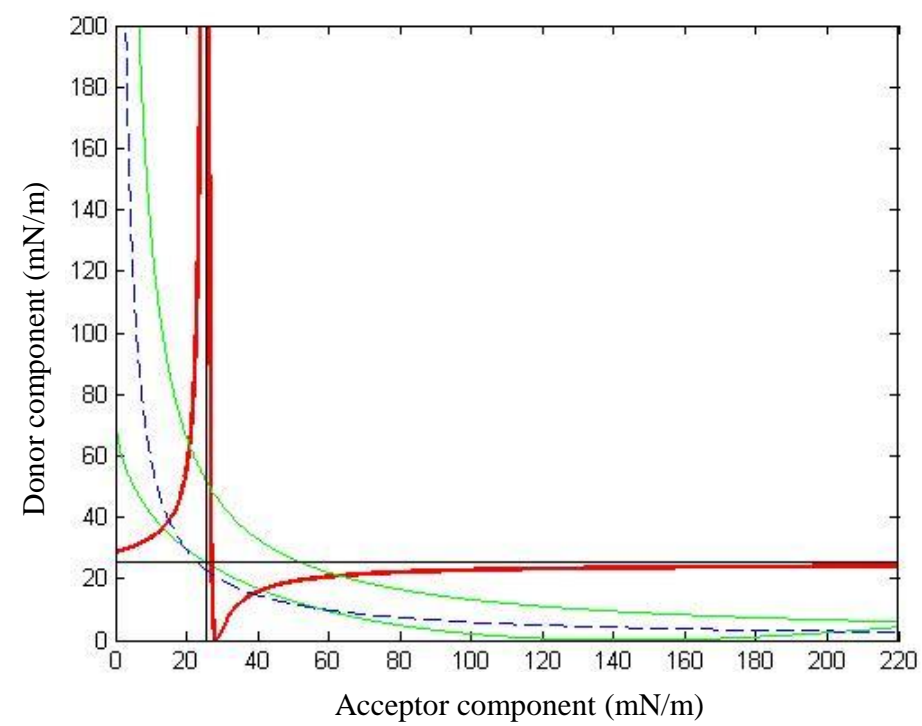

Figure S5. The protein-protein interaction map. The lower green contour represents equation S15, above which a minimum exists in the initial distribution. The higher green contour indicates where $\gamma^{l w}{ }_{3}$ is equal to zero. Therefore, between these boundaries lies the region in which adsorption onto the silica layer can occur. The horizontal (vertical) black lines represent when $\gamma_{3}^{d}\left(\gamma_{3}^{a}\right)$ and $\gamma_{2}^{d}\left(\gamma_{2}^{a}\right)$ are equal. Hence these lines separate the map into regions of $\mathrm{G}^{\mathrm{da} \|}{ }_{323}$ greater (top left/bottom right) and less than (top right/ bottom left) zero. An example contour with $\gamma_{3}^{l w}=40 \mathrm{mN} / \mathrm{m}$ is plotted in the dotted blue. The red contours represent equation S15, above this line in the top left region repulsion exists, whilst repulsion exists below this in the bottom right region.

By increasing the $\gamma^{l w}{ }_{3}$ component, the depth of the minimum is increased, and by having a $\mathrm{G}^{\mathrm{da} \|_{323}}$ value closer to the horizontal or vertical black lines the strength of the repulsion is decreased. The values for the surface tension of COE-3 were chosen such that sufficient repulsion (filling of the potential well) was exhibited to recover the experimental data. This only occurred for the surface tension values stated in the main paper because the depth of the minimum and strength of the repulsion are both extremely sensitive. 


\section{$\underline{\text { References S }}$}

(1) Saphire, E. O.; Parren, P. W.; Pantophlet, R.; Zwick, M. B.; Morris, G. M.; Rudd, P. M.; Dwek, R. A.; Stanfield, R. L.; Burton, D. R.; Wilson, I. A. Crystal Structure of a Neutralizing Human IgG Against HIV-1: A Template for Vaccine Design. Science. 2001, 293 (5532), 1155-1159.

(2) Van Oss, C. Interfacial Forces in Aqueous Media; Marcel Dekker, 1994.

(3) Cacace, M. G.; Landau, E. M.; Ramsden, J. J. The Hofmeister Series: Salt and Solvent Effects on Interfacial Phenomena. Q. Rev. Biophys. 1997, 30 (3), S0033583597003363.

(4) Fowkes, F. M. Additivity of Intermolecular Forces at Interfaces: I. Determination of the Contribution to Surface and Interfacial Tensions of Dispersion Forces in Various Liquids. J. Phys. Chem. 1963, 67 (12), 2538-2541.

(5) Salgin, S.; Salgin, U.; Bahadir, S. Zeta Potentials and Isoelectric Points of Biomolecules: The Effects of Ion Types and Ionic Strengths. Int. J. Electrochem. Sci. 2012, 7 (12), 12404-12414.

(6) Behrens, S. H.; Grier, D. G. The Charge of Glass and Silica Surfaces. J. Chem. Phys. 2001, 115 (14), 6716-6721.

(7) Giupponi, G.; Pagonabarraga, I. Determination of the Zeta Potential for Highly Charged Colloidal Suspensions. Philos. Trans. R. Soc. A Math. Phys. Eng. Sci. 2011, 369 (1945), 2546-2554. 